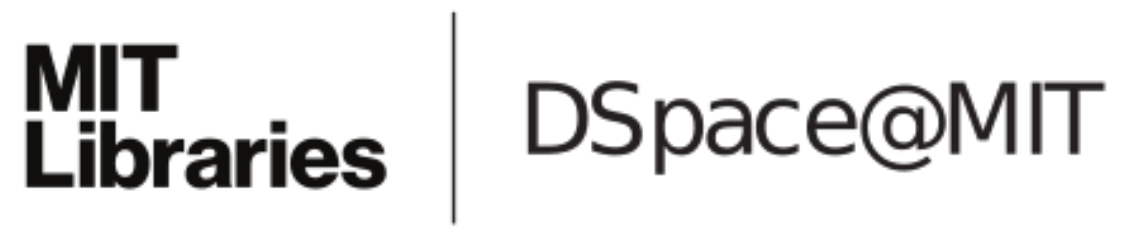

MIT Open Access Articles

Formation of Nanocrystalline and Amorphous Materials

Causes Parallel Brittle\#Viscous Flow of Crustal

Rocks: Experiments on Quartz\#Feldspar Aggregates

The MIT Faculty has made this article openly available. Please share how this access benefits you. Your story matters.

Citation: Pec, Matej and Saleh Al Nasser. "Formation of nanocrystalline and amorphous materials causes parallel brittle-viscous flow of crustal rocks: Experiments on quartz-feldspar aggregates." Journal of Geophysical Research: Solid Earth 126, 5 (May 2021): e2020JB021262. () 2021 American Geophysical Union

As Published: http://dx.doi.org/10.1029/2020jb021262

Publisher: American Geophysical Union (AGU)

Persistent URL: https://hdl.handle.net/1721.1/133157

Version: Original manuscript: author's manuscript prior to formal peer review

Terms of use: Creative Commons Attribution-Noncommercial-Share Alike 


\title{
Formation of Amorphous Materials Causes Parallel Brittle-viscous Flow of Crustal Rocks: Experiments on Quartz - Feldspar Aggregates
}

\author{
Matej Pec $^{1}$, Saleh Al Nasser ${ }^{1}$ \\ ${ }^{1}$ Department of Earth, Planetary and Atmospheric Science. Massachusetts Institute of Technology, Cambridge, \\ Massachusetts 02139, USA
}

Key Points:

- Strain localizes into viscous slip zones that delimit coarser-grained, cataclastic lenses.

- Viscous flow is enabled by a microstructural transformation from crystalline to partly amorphous material in the slip zones.

- Both viscous and brittle processes have to operate in parallel to accommodate deformation

Corresponding author: Saleh Al Nasser, sa lehn@mit . edu 


\begin{abstract}
The brittle - viscous transition in the lithosphere occurs in a region where many large earthquakes nucleate. To study this transition, we sheared bi-mineralic aggregates with varying ratio of quartz and potassium feldspar at temperature, $\mathrm{T}=750^{\circ} \mathrm{C}$ and pressure, $P_{c}=800 \mathrm{MPa}$ under either constant displacement rate or constant load boundary conditions. Under constant displacement rate, samples reach high shear stress $(\tau=0.4-1 \mathrm{GPa})$ depending on mineral ratio) and then weaken. Under constant load, the strain rate shows low sensitivity to stress below $\tau \approx 400 \mathrm{MPa}$, followed by a high stress sensitivity (stress exponent, $n=9-13$ ) at higher stresses irrespective of mineral ratio. Strain is localized along "slip zones" in a $\mathrm{C}$ and $\mathrm{C}^{\prime}$ orientation. The material in the slip zones shows extreme grain size reduction and flow features. At peak strength, 1-2 vol\% of the sample is composed of slip zones that are straight and short. With increasing strain, the slip zones become anastomosing and branching and occupy up to $9 \mathrm{vol} \%$; this development is concomitant with strain-weakening of the sample. Slip zones delimit larger cataclastic lenses, which develop a weak foliation. Our results suggest that strain localization leads to microstructural transformation of the rocks from a crystalline solid to an amorphous, fluid-like material in the slip zones. The measured rheological response is a combination of viscous flow in the slip zones and cataclastic flow in coarser-grained lenses and can be modeled as a frictional slider coupled in parallel with a viscous dashpot.
\end{abstract}

\title{
1 Introduction
}

Relative motion of tectonic plates is accommodated along lithosphere-scale shear zones. The strength and stability of these shear zones control large scale tectonics and the location of earthquakes (Bürgmann \& Dresen, 2008; Molnar, 2020). Laboratory-derived strength profiles of the lithosphere postulate that the strength in the upper crust is controlled by frictional sliding along pre-existing fractures, while the strength of the lower crust and upper mantle is controlled by viscous flow of rocks (Goetze \& Evans, 1979; Brace \& Kohlstedt, 1980; Kohlstedt et al., 1995). In this traditional view of the strength of the lithosphere, the transition from frictional sliding to viscous flow is abrupt and occurs at the intersection of Byerlee's rule with a dislocation creep flow law for a mineral of choice deforming at a constant strain rate. This sharp "brittle - viscous" transition is expected in monomineralic aggregates as the activation energy, stress, and pressure sensitivities of brittle and viscous steady-state processes are vastly different (Reber \& Pec, 2018).

Add odds with this model, experimental observations document that many rocks and minerals deform by "semi-brittle" flow - i.e. parallel or sequential operation of brittle (fracturing, cataclastic flow, and frictional sliding) and viscous (diffusion, dislocation and dissolution-precipitation creep and grain boundary sliding) deformation processes - over a broad range of P-T- $\dot{\gamma}$ conditions (Carter \& Tsenn, 1987; Chester, 1988; Fredrich et al., 1989; Fredrich et al., 1990; Hirth \& Tullis, 1994, Pec et al., 2012; Pec et al., 2016; Reber et al., 2015; Richter et al., 2018; Marti et al., 2020; Okazaki \& Hirth, 2020). These studies are corroborated by field observations that document an interplay between brittle and viscous deformation processes in a range of tectonic settings under greenschist to granulite facies conditions - from the grain-scale to the outcropscale - suggesting that semi-brittle rheology is common in nature as well (Simpson, 1985; FitzGerald \& Stünitz, 1993; Stünitz \& FitzGerald, 1993; Mancktelow \& Pennacchioni, 2004; Pennacchioni et al., 2006; Pennacchioni \& Mancktelow, 2007; Fusseis \& Handy, 2008; Menegon et al., 2013; Hayman \& Lavier, 2014; Okudaria et al., 2015; Bukovská et al., 2016).

Given the importance of semi-brittle deformation in nature and experiment, numerous theoretical models were developed to account for the observed behavior (Bos \& Spiers, 2002; Noda \& Shimamoto, 2012; Lavier et al., 2013; Aharonov \& Scholz, 2019; Beall et al., 2019; Jacquey \& Cacace, 2020a; Jacquey \& Cacace, 2020b; Parisio et al., 2020). Despite notable differences between the individual models, all agree on the fact that rocks are expected to reach their peak strength around the brittle - viscous transition. Therefore, constraining the rheology and deformation mechanisms of rocks deforming in the semi-brittle flow regime is crit- 
a)

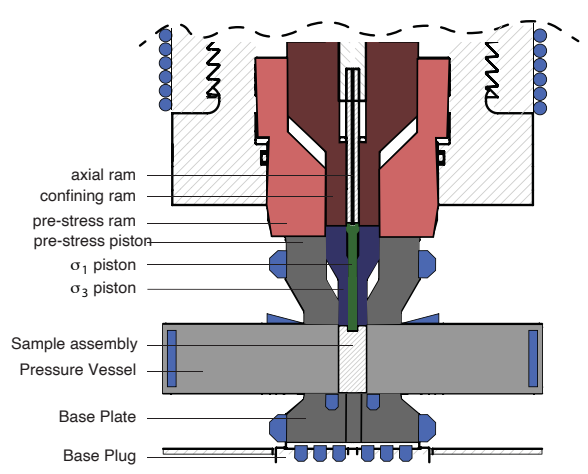

b)

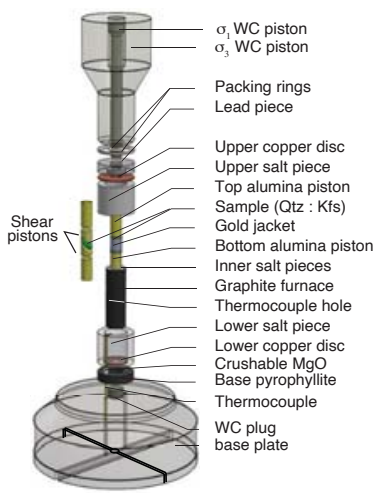

c)

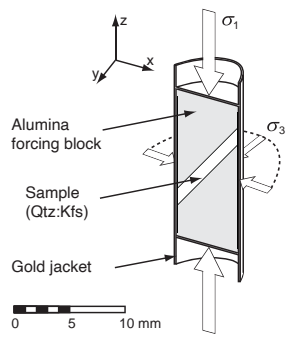

Figure 1. Schematic of experimental apparatus and the sample assembly. a) cross-section of the GriggsType apparatus. b) Detailed schematic of the assembly components (modified after Precigout et al., 2018). c)

Geometry of the sample.

ical for improving our understanding of the rheology of the lithosphere as well as the mech-

In this study, we investigate the behavior of Qtz and Kfs aggregates; both are abundant minerals in the continental crust (Wedepohl, 1995) and hence present a simplified bi-mineralic system. We explore the effect of composition on semi-brittle flow by varying the ratio of Qtz:Kfs. find that strain localizes into nano-crystalline partially amorphous slip zones that delimit in the majority of the fault rocks volume, localization into thin, viscously deforming, slip zones plays a critical role in strain accommodation at high-stress conditions accompanying semi-brittle flow. Fault slip is likely stabilized by the (linear?) viscous rheology of the slip zones.

\section{Materials and Methods}

We conducted a series of general shear experiments using a Griggs-type servo-hydraulically driven deformation apparatus installed at MIT and described in Ghaffari \& Pec (2020). Figpresent a detailed description of starting materials and experimental and analytical methodology.

\subsection{Starting Materials \& Sample Assembly}

Gem quality Brazil quartz single crystals and a large orthoclase single crystal were crushed using a mortar and pestle and sieved to obtain grain size $<100 \mu \mathrm{m}$. Subsequently, the crushed powder was grain size separated via Stokes settling in ethanol as described in De Ronde (2004). We used a grain size aliquot of $10-20 \mu \mathrm{m}$ for both minerals in all experiments. To obtain starting materials with a range of compositions, we mixed the Qtz and Kfs powders in a 7:3, 1:1, or 3:7 ratio by weight. $0.1 \mathrm{~g}$ of these powders were placed between two alumina forcing blocks that were pre-cut at $45^{\circ}$. We added $0.1 \mu \mathrm{L}$ of distilled water to the sample, resulting in $\mathrm{H}_{2} \mathrm{O}$ content of $0.1 \mathrm{wt} \%$. The sample is weld-sealed in a $0.2 \mathrm{~mm}$ wall-thickness gold jacket, placed between the top and bottom alumina pistons, and surrounded by solid $\mathrm{NaCl}$ salt. A graphite resistivity furnace is used to heat the sample. The temperature at the center of the sample is controlled using a k-type thermocouple. The whole assembly is placed in a water-cooled pres- 
sure vessel with a deformable lead $(\mathrm{Pb})$ disc on the top that transmits load from $\sigma_{1}$ and $\sigma_{3}$ pistons to the sample assembly (Figure 1).

\subsection{Experimental Procedure}

To determine the material's melting temperature, hot-press experiments of the 1:1 Qtz:Kfs samples were performed at confining pressure $P_{c}=810 \mathrm{MPa}$ and temperature, $\mathrm{T}=800^{\circ} \mathrm{C}$ and $900^{\circ} \mathrm{C}$. At $900^{\circ} \mathrm{C}$ melting was visible under SEM, while no melt could be detected at $800^{\circ} \mathrm{C}$. Therefore $750^{\circ} \mathrm{C}$ was chosen for the subsequent experiments to confidently stay below the solidus of the rocks. All samples were first hot-pressed at $\mathrm{T}=750^{\circ} \mathrm{C}$ and $\mathrm{Pc}=810 \mathrm{MPa}$ for $\approx 20$ hours. After hot pressing, the samples were deformed either at an approximately constant displacement rate or under constant load. The conditions of the experiments are summarized in Table 1.

\subsubsection{Constant Displacement Rate Experiments}

In constant displacement rate experiments, the $\sigma_{1}$ piston of the apparatus was driven at $\dot{d}_{x}=6.85 \times 10^{-4} \mathrm{~mm} \mathrm{~s}^{-1}$ resulting in a strain rate of $\dot{\gamma} \approx 8 \times 10^{-4} \mathrm{~s}^{-1}$ in the samples. This rate was achieved by specifying a constant flow rate of oil into the rig's pressurizing chamber. At the same time, the confining pressure $\left(\sigma_{3}\right)$ was controlled and held constant at $810 \mathrm{MPa}$ by a $\sigma_{3}$ syringe pump. The experiments were terminated after the samples reached the desired finite strain by quenching to $200^{\circ} \mathrm{C}$ in approximately 500s while simultaneously decreasing the differential stress. Finally, temperature, axial load, and confining pressure were brought down to room conditions.

\subsubsection{Constant Load Experiments}

In constant load experiments, we deformed the sample in several load steps while the confining pressure $\left(\sigma_{3}\right)$ was held constant at $810 \mathrm{MPa}$. First, $\sigma_{1}$ piston was driven at a constant displacement rate of $\dot{d}_{x} \approx 6.85 \times 10^{-4} \mathrm{~mm}$ until it hits the sample. After reaching a desired value of load past the hit-point, the axial load is held constant with the $\sigma_{1}$ syringe pump until a steady-state displacement rate is reached. Multiple creep deformation steps at a range of stress levels were performed until the sample has reached the desired amount of strain. Finally, the sample was quenched and brought back to room conditions at the same rate as the constant displacement rate experiments.

\section{Analysis}

\subsection{Mechanical Data Analysis}

Data was logged at 1 sample/s (load, sample temperature, furnace power (Volts \& Ampers in the heating circuit), confining pressure, position of the $\left(\sigma_{1}\right)$ and $\left(\sigma_{3}\right)$ pistons). The acquired data is uploaded into Matlab and evaluated using the program "newRIG" (https://mpec.scripts.mit.edu/peclab/software/). Displacement data are corrected for rig stiffness $(6.1 \mu \mathrm{m} / \mathrm{kN})$. The recorded vertical displacement data of the $\sigma_{1}$ piston was resolved into a thinning component on the sample perpendicular to the shear zone boundary, and a shear component parallel to the shear zone boundary. To simplify the shear strain calculation, the thinning rate is assumed to be linear and constant throughout the deformation. The reported finite shear strain derived from mechanical data, $\gamma_{m}$, is summed from incremental shear strains, which are calculated as the incremental shear zone parallel displacement divided by the instantaneous thickness. While this calculation is standard in rock mechanics, it overestimates the "true shear strain" as thinning is not taken properly into account (see discussion in Heilbronner \& Kilian, 2017). 
Shear stress is calculated from the load cell record corrected for "friction" $(1.3 \mathrm{kN} / \mathrm{mm}$, see appendix of Tarantola et al., 2012) and corrected for decreasing forcing block overlap as the slip increases.

\subsection{Image Acquisition for Microstructural Analysis}

Thin sections parallel to the displacement direction and perpendicular to the shear zone boundary were prepared from the deformed samples and imaged using a polarizing light microscope and a Zeiss Merlin Field Emission Scanning Electron Microscope (SEM). In the SEM, an acceleration voltage of $15 \mathrm{kV}$ and a beam current of $2 \mathrm{nA}$ were used to obtain high-resolution backscatter electron (BSE) images, which could be used to distinguish different minerals based on their brightness and analyze the shape preferred orientation (SPO) of the individual phases.

To determine the SPOs, we use the autocorrelation function which quantifies the orientation(s) of features present in an image and their correlation length-scale (Heilbronner, 2002; Heilbronner \& Barrett, 2013). The advantage of this approach is that it does not require the segmentation of an image and captures the sample's general structure. The disadvantage is that the ACF analysis considers all features present in the image, including undesirable features that form at the end of the controlled part of the experiment, such as unloading cracks, dust speckles, etc.; care has to be exercised when interpreting the data. In some cases, we analyze each mineral phase separately by creating bitmaps for each phase via grey-level thresholding. In all cases, we measure the aspect ratio of the thresholded ACF ellipse to quantify the magnitude of anisotropy in the fabric. We measure angles counterclockwise from $0^{\circ}$ (positive $\mathrm{x}$ direction) to $180^{\circ}$ with $0^{\circ}$ corresponding to the positive $\mathrm{x}$-axis; the upper hemisphere is positive and the lower hemisphere is negative. $+/-90^{\circ}$ corresponds to a feature perpendicular to the shear zone boundary. Orientations in the upper hemisphere $<90^{\circ}$ are called "synthetic" and $>90^{\circ}$ are called "antithetic" to the shear. Note that as SPO measurements are not directional, $-45^{\circ}$ and $135^{\circ}$ are complementary orientations that correspond to the macroscopic loading direction (see Figure 2). All images are oriented so that the shear zone is horizontal, and the top is shearing to the right. Analysis of the images was performed using ImageSXM http://www.liv.ac.uk/ sdb/ImageSXM/, Photoshop ${ }^{T M}$ and Fiji"https://fiji.sc/", with Jazy macros https://github.com/kilir/Jazy_macros.

To characterize the morphology of zones of localized strain (termed "slip zones" and described in detail in Section 4.2.1), we used an improved box-counting technique (Roy et al., 2007) to perform fractal geometry analysis. The estimated fractal geometry dimension ( $D$ between 0 and 2) indicates the complexity of the studied feature; the higher the $(D)$ value, the more complex the pattern.

To evaluate the crystallographic preferred orientation (CPO) of the samples, we analyzed two samples using Electron Backscattered Diffraction (EBSD) at the University of Tromsø. EBSD maps were obtained on a Zeiss Merlin field emission SEM equipped with an Oxford EBSD camera at $20 \mathrm{kV}$ acceleration voltage and a step size of $0.4 \mu \mathrm{m}$. Data was iteratively cleaned up using EBSDInterp Matlab code (Pearce, 2015) that uses band contrast quality to inform data reconstruction. After the initial clean up, all data processing was performed using the MTEX toolbox (https://mtex-toolbox.github.io/ e.g. Mainprice et al., 2011)

\section{Results}

\subsection{Mechanical Data}

The strength of the rocks depends on the mineral composition in a non-trivial manner. Samples with a 1:1 ratio of Qtz: Kfs reached the highest peak shear stress of $\approx 1 \mathrm{GPa}$. Samples with a 3:7 ratio of Qtz:Kfs are the weakest with a peak shear stress between $0.4-0.6$ GPa. Samples with a $7: 3$ ratio of Qtz:Kfs reached intermediate peak shear stress of $\approx 0.72$ $\mathrm{GPa}$ as we present in Figure 3. The mechanical data in the constant displacement rate exper- 


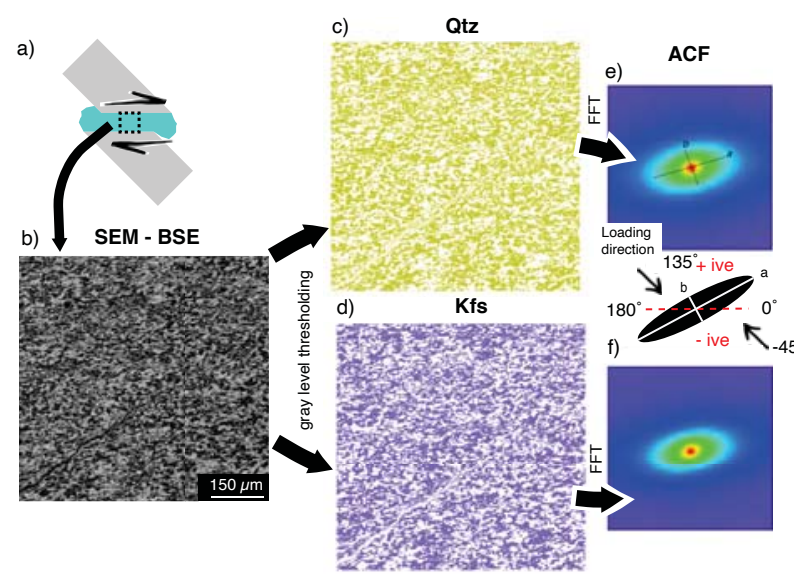

Figure 2. Image analysis workflow and angle measurement conventions. a) schematic of a sample thin section. All images are sheared top-to-the right. Gray are forcing blocks, blue is sample. b) SEM-BSE image collected from the center of the sample (dashed rectangle in a), c) \& d) binary images containing Qtz and Kfs obtained by gray level thresholding of SEM-BSE image. e) \& f) center of a autocorrelation function computed via fast furrier transform. Inset shows the angle convention and definition of fabric anisotropy (b/a of the ACF ellipse). In some cases ACF analysis is applied directly to the SEM-BSE image. See text for details.

iments with the same composition shows good reproducibility except for the samples with Qtz:Kfs ratio of 3:7 where $\mathrm{a} \approx 200 \mathrm{MPa}$ difference in shear stress is observed. The peak stress of the 1:1 ratio samples also occurs at higher strain $(\gamma \approx 1.5)$ than for the rest of the samples that reach peak stress at $\gamma \approx 1$. Post-peak weakening is associated with a transient increase in displacement rate by up to a factor of $6-16$, followed by a monotonic decrease of displacement rate (Figure 3). A secondary change in the weakening rate, corresponding to a secondary deceleration in displacement rate, can be observed in experiments taken to the highest strains (Figure $3 a$ and $3 b$ ).

In Figure 4, data from experiments at peak stress is represented in Mohr space. The dominant slip zone orientations (see Section 4.2.1) are shown by full circles and roughly form where normal stress-dependent, dilatant failure would be expected. Most of our experiments were deformed at lower differential stress than that predicted by Byerlee's rule and higher differential stress than Goetze's criterion (Goetze \& Evans, 1979) as is expected for experiments deformed in a semi-brittle flow regime (Figure 4). The friction coefficient, $\mu$, calculated for the $45^{\circ}$ pre-cut as $\mu=\frac{\tau}{\sigma_{n}}$, is the highest $(0.54)$ in the Qtz:Kfs 1:1 ratio samples, and lowest $(0.32)$ in the Qtz:Kfs 3:7 samples. Only the 1:1 Qtz:Kfs ratio samples plot close to the Byerlee's rule envelope (Figure 4).

Data from constant load experiments presented in Figure 5 show three distinct trends: a) at low stress $(\tau<100 \mathrm{MPa})$ and strain $(\gamma<1)$, the increase in stress leads to decrease in strain rate possibly due to porosity collapse and ongoing compaction of the assembly at early stages of the experiment, b) at intermediate stress (100 MPa $>\tau<400 \mathrm{MPa})$ and higher strains $(0.5>\gamma<1)$, the strain rate sensitivity to stress is low to none (assuming a power-law relationship between strain rate and stress, $\dot{\gamma}=\tau^{n}$ we obtain $\mathrm{n} \approx 1.2$ in one experiment, while the other experiment shows no dependence of strain rate on stress), c) at high stress ( $\tau>400$ MPa) and strain $(\gamma=>1)$, the strain rate sensitivity to stress sensitivity is high $(\mathrm{n}=9-13)$.

The strain rate at each stress step used in Figure 5 is estimated by computing the slope of strain vs. time over a selected time interval (see Figure 6 for details). Toward the end of both experiments (SN019 \& SN020), we observed an acceleration in the strain rate by up to 


\begin{tabular}{|c|c|c|c|c|c|c|c|c|c|c|c|c|c|}
\hline Sample & $\begin{array}{l}\text { Qtz: } \\
K f s\end{array}$ & $T\left({ }^{\circ} C\right)$ & $\begin{array}{l}\text { Hot Pressing } \\
\text { Time }(h)\end{array}$ & $\begin{array}{l}\text { Deformation } \\
\text { Time }(s)\end{array}$ & $\dot{d_{x}}\left(\mathrm{~ms}^{-1}\right)$ & $\dot{\gamma}\left(s^{-1}\right)$ & $\gamma_{a}$ & $\gamma_{m}$ & $P_{C}(M P a)$ & $\tau(M P a)$ & $\sigma_{n}(M P a)$ & $\mu$ & $\begin{array}{l}\text { Thickness } \\
(\mathrm{mm})\end{array}$ \\
\hline $\begin{array}{l}\text { SN011 } \\
\text { SNO12 }\end{array}$ & $1: 1$ & $\begin{array}{l}900 \\
800\end{array}$ & 10.6 & $N / A$ & $N / A$ & $N / A$ & 0.5 & $\begin{array}{l}0 \\
0\end{array}$ & 810 & $N / A$ & $N / A$ & $N / A$ & 0.86 \\
\hline $\begin{array}{l}\text { SN012 } \\
\text { SN014 }\end{array}$ & $\begin{array}{l}1: 1 \\
1: 1\end{array}$ & $\begin{array}{l}800 \\
750\end{array}$ & $\begin{array}{l}4.6 \\
19.4\end{array}$ & $\begin{array}{l}N / A \\
3209\end{array}$ & $\begin{array}{l}N / A \\
6.33 \times 10^{-4}\end{array}$ & $\begin{array}{l}N / A \\
100 \times 10-3\end{array}$ & 0.9 & & $\begin{array}{l}810 \\
810\end{array}$ & $N / A$ & $N / A$ & $N / A$ & $\begin{array}{l}0.89 \\
0.73\end{array}$ \\
\hline $\begin{array}{l}\text { SNO14 } \\
\text { SN015 }\end{array}$ & $\begin{array}{l}1: 1 \\
3: 7\end{array}$ & 750 & $\begin{array}{l}19.4 \\
19.8\end{array}$ & 1790 & $6.47 \times 10^{-4}$ & $1.10 \times 10^{-3}$ & 2.6 & 2.84 & 810 & 938 & 1783 & 0.53 & 0.73 \\
\hline $\begin{array}{l}\text { SNO15 } \\
\text { SN016 }\end{array}$ & $7: 3$ & 750 & 18.8 & 2284 & $5.65 \times 10^{-4}$ & $9.06 \times 10^{-4}$ & 1.9 & 1.68 & 859 & 406 & 1283 & 0.32 & 0.74 \\
\hline SN017 & $7: 3$ & 750 & 19.3 & 2156 & $6.01 \times 10^{-4}$ & $9.98 \times 10^{-4}$ & 1.2 & 189 & 811 & 720 & 1534 & 0.46 & 0.94 \\
\hline SN036 & $3: 7$ & 750 & 20 & 1846 & $5.97 \times 10^{-4}$ & $9.62 \times 10^{-4}$ & $N / A$ & 1.61 & 810 & 607 & 1440 & $\begin{array}{l}0.40 \\
0.42\end{array}$ & $\begin{array}{l}0.83 \\
N / A\end{array}$ \\
\hline SN069 & $1: 1$ & 750 & 19.2 & 2484 & $4.88 \times 10^{-4}$ & $7.84 \times 10^{-4}$ & $N / A$ & 1.74 & 810 & 1009 & 1863 & 0.54 & $N / A$ \\
\hline SN019* & $1: 1$ & 750 & 18.0 & $\begin{array}{l}9159 \\
8491 \\
5670 \\
5720 \\
5350 \\
41290 \\
5570 \\
1790 \\
410\end{array}$ & $\begin{array}{l}4.89 \times 10^{-4} \\
1.88 \times 10^{-4} \\
1.64 \times 10^{-4} \\
1.12 \times 10^{-4} \\
1.12 \times 10^{-4} \\
1.27 \times 10^{-5} \\
1.37 \times 10^{-4} \\
7.88 \times 10^{-4} \\
4.26 \times 10^{-3}\end{array}$ & $\begin{array}{l}1.62 \times 10^{-5} \\
7.22 \times 10^{-6} \\
6.61 \times 10^{-6} \\
6.51 \times 10^{-6} \\
6.02 \times 10^{-6} \\
2.42 \times 10^{-6} \\
7.41 \times 10^{-6} \\
2.78 \times 10^{-5} \\
1.20 \times 10^{-4}\end{array}$ & 1.8 & 2.39 & 811 & $\begin{array}{l}21.8 \\
103.1 \\
186.8 \\
273.1 \\
361.7 \\
456.6 \\
551.7 \\
648.1 \\
745.8\end{array}$ & $\begin{array}{l}908 \\
982.8 \\
1058 \\
1132 \\
1207 \\
1282 \\
1356 \\
1430 \\
1504\end{array}$ & $\begin{array}{l}0.02 \\
0.11 \\
0.18 \\
0.24 \\
0.30 \\
0.35 \\
0.42 \\
0.45 \\
0.50\end{array}$ & 0.84 \\
\hline $\mathrm{SN} 020^{*}$ & $3: 7$ & 750 & 19.8 & $\begin{array}{l}4743 \\
4284 \\
57393 \\
3890 \\
4720 \\
4520 \\
6260 \\
3930 \\
2520 \\
1810 \\
1280 \\
1270 \\
58180 \\
3100 \\
1600 \\
1500 \\
900 \\
800\end{array}$ & $\begin{array}{l}2.7 \times 10^{-4} \\
1.74 \times 10^{-6} \\
2.01 \times 10^{-5} \\
1.15 \times 10^{-4} \\
1.17 \times 10^{-4} \\
7.24 \times 10^{-5} \\
6.59 \times 10^{-5} \\
1.12 \times 10^{-4} \\
1.91 \times 10^{-4} \\
1.71 \times 10^{-4} \\
3.57 \times 10^{-4} \\
6.54 \times 10^{-4} \\
1.7 \times 10^{-5} \\
1.70 \times 10^{-4} \\
2.50 \times 10^{-4} \\
2.06 \times 10^{-4} \\
1.00 \times 10^{-3} \\
9.2 \times 10^{-3}\end{array}$ & $\begin{array}{l}1.18 \times 10^{-5} \\
8.05 \times 10^{-6} \\
1.12 \times 10^{-6} \\
5.58 \times 10^{-6} \\
2.41 \times 10^{-6} \\
3.53 \times 10^{-6} \\
2.81 \times 10^{-6} \\
3.61 \times 10^{-6} \\
7.90 \times 10^{-6} \\
8.37 \times 10^{-6} \\
1.12 \times 10^{-5} \\
2.35 \times 10^{-5} \\
6.35 \times 10^{-7} \\
1.17 \times 10^{-5} \\
8.37 \times 10^{-6} \\
7.01 \times 10^{-6} \\
3.13 \times 10^{-5} \\
1.33 \times 10^{-4}\end{array}$ & $N / A$ & 2.07 & 811 & $\begin{array}{l}5.2 \\
30.4 \\
56.2 \\
81.8 \\
108.2 \\
148.0 \\
174.8 \\
201.9 \\
242.8 \\
291.2 \\
340.2 \\
397.1 \\
112.0 \\
349.9 \\
400.3 \\
457.4 \\
516.5 \\
577\end{array}$ & $\begin{array}{l}816 \\
841 \\
866 \\
890 \\
915 \\
952 \\
977 \\
1003 \\
1040 \\
1083 \\
1127 \\
1177 \\
921 \\
1132 \\
1176 \\
1226 \\
1275 \\
1324\end{array}$ & $\begin{array}{l}0.01 \\
0.04 \\
0.06 \\
0.09 \\
0.12 \\
0.16 \\
0.18 \\
0.20 \\
0.23 \\
0.27 \\
0.30 \\
0.34 \\
0.12 \\
0.31 \\
0.34 \\
0.37 \\
0.41 \\
0.44\end{array}$ & 0.84 \\
\hline
\end{tabular}

Table 1. Summary of mechanical data. $\dot{d}_{x}-\sigma_{1}$ piston displacement rate, $\dot{\gamma}$ - shear strain rate, $\gamma_{a}$ - strain estimated from thin section, $\gamma_{m}$ - strain calculated based on mechanical data. $P_{c}$ - confining pressure, $\tau$ - peak shear stress, $\sigma_{n}$ - maximum normal stress resolved on $45^{\circ}$ pre-cut, $\mu$ is the friction coefficient at peak stress on $45^{\circ}$ pre-cut.

*constant load experiments.

2 orders of magnitude accompanied by unstable load control due to abrupt sample weakening. This phase is also accompanied by a slight decrease in the recorded temperature by $\approx$ $0.5^{\circ} \mathrm{C}$ and an increase in furnace output (Figure 6). This acceleration in strain rate under constant load occurs at the same strain as peak stress in constant displacement rate experiments with identical Qtz:Kfs ratios $(\gamma=1 \& 1.5$, compare Figures $3 \& 6)$. 

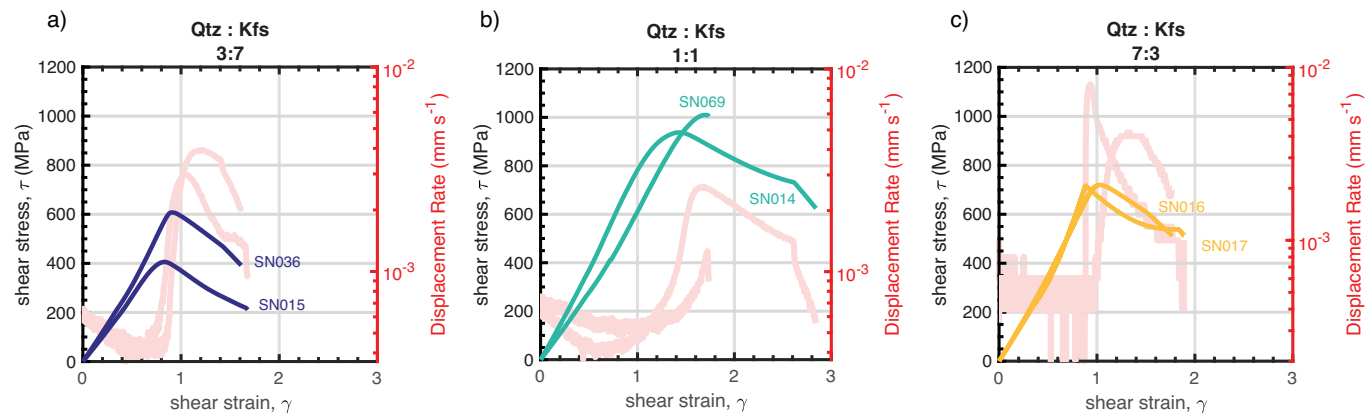

Figure 3. Mechanical data for constant displacement rate experiments: stress - strain curves. Shear stress vs. strain rate and $\sigma_{1}$ piston displacement rate for a) 3:7, b) 1:1, c) 7:3 Qtz : Kfs ratio samples.

a)

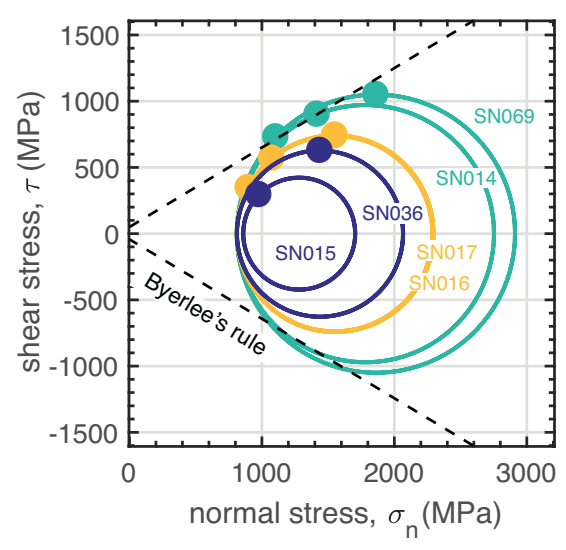

b)

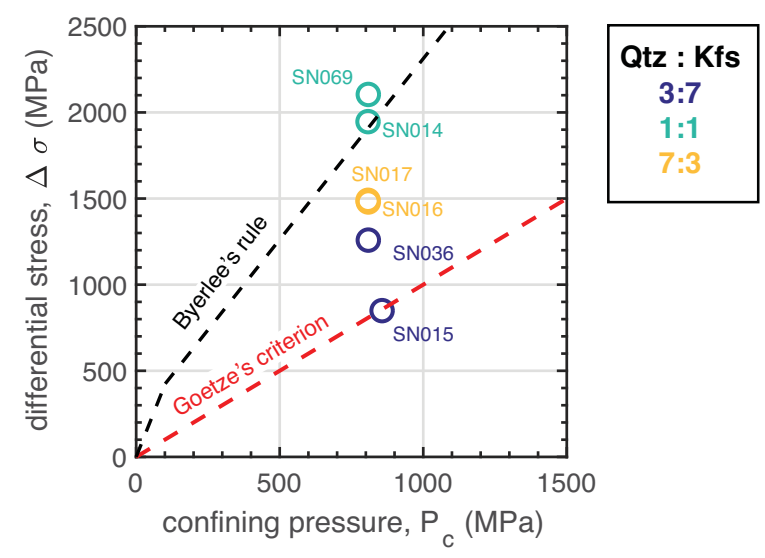

Figure 4. Mechanical data from constant displacement rate experiments: Mohr space a) Mohr circles at peak strength, dashed line represents Byerlee's rule. Full circles show measured orientations of slip zones (see text for details) b) Data from all experiments plotted in a differential vs. confining pressure space. 


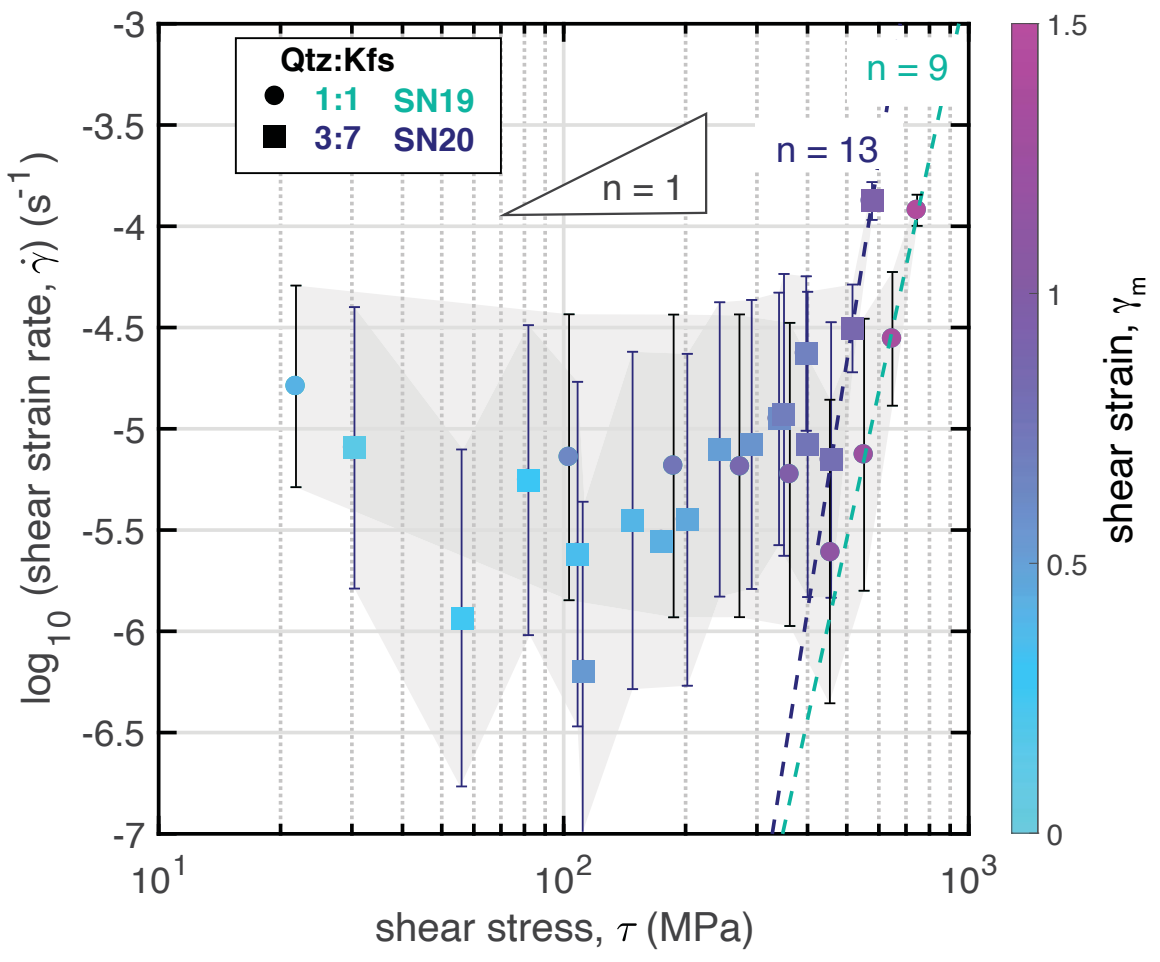

Figure 5. Mechanical data from constant load experiments: $\log (\tau)$ vs. $\log (\dot{\gamma})$ data color coded by mean strain at stress step. Error bars and shaded regions show 1 standard deviation (s.t.d). The high strain rate at low stress $(<100 \mathrm{MPa})$ can be attributed to the early compaction of the samples. Notice that 1:1 Qtz: Kfs ratio samples are stronger than 3:7 Qtz: Kfs ratio samples and reach high stresses at higher strains (compare to Figure 3). Last 3 stress steps are fitted with a least squares linear fit and yield high stress exponents $(n=9-$ 13). See text for details. 


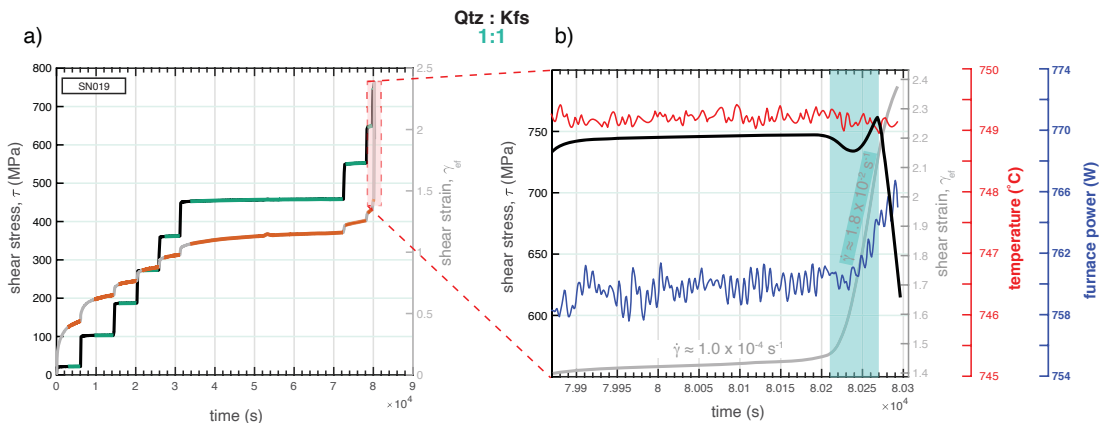

c)

$\begin{array}{ccc}\text { Qtz }: \text { Kfs } \\ 3: 7 & \text { d) }\end{array}$
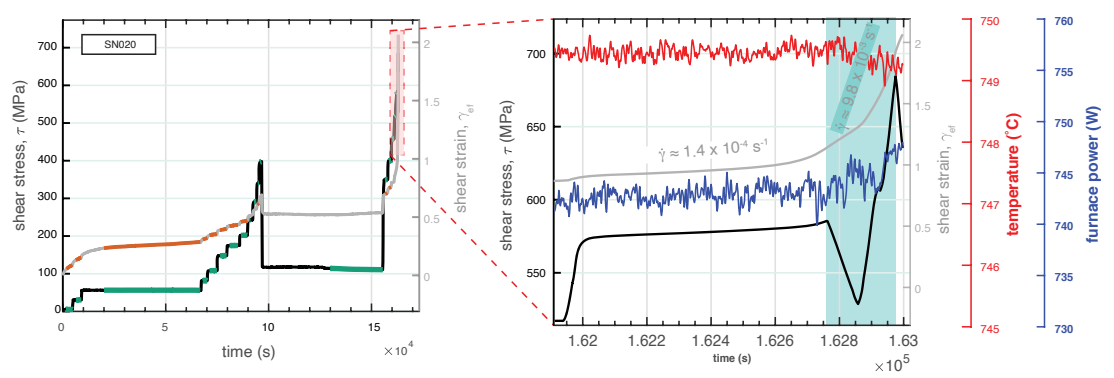

Figure 6. Mechanical data from constant load experiments: a) \& c) $\tau$ and $\dot{\gamma}$ vs. time. Strain rate is estimated by calculating the slope of strain vs. time curves over a time interval highlighted in orange. b) \& d) show the behavior of the system at the end of both experiments. Both experiments show an acceleration in the strain rate accompanied by a decrease in the temperature and an increase in the furnace power. 


\subsection{Micro-structural Observation}

To gain further insight into the physical processes responsible for the observed mechanical behavior, we analyzed the resulting microstructures in SEM-BSE images \& EBSD data.

In deformed samples, we observe the localization of strain into "slip zones" which delimit larger "lenses" of pervasively fractured fault rock. We first describe the slip zones in detail below.

\subsubsection{Slip Zones}

The slip zones nucleate at the outer shear zone boundaries and propagate inward with increasing strain. Two dominant orientations are observed, a C' orientation (angles ranging from $170^{\circ}$ to $150^{\circ}$ relative to the shear zone boundary), and a $\mathrm{C}$ orientation $\left(\approx 0^{\circ}\right.$, parallel to shear zone boundary) which is observed in a number of samples typically at the shear zone - forcing block interface as shown in Figure 7.

The slip zones are better developed in samples sheared to high shear strains and with higher Kfs content. The degree of strain localization is well visible at the jacket - shear zone interface where protrusion of the jacket into the shear zone marks the presence of a slip zone. Some shear zones in Figure 7 appear sheared in the opposite sense (top to the left); however, this is in fact, not the case. All samples start as parallelepipeds inclined to the left due to the filling of the starting material powder into the jacket on top of the $45^{\circ}$ pre-cut forcing blocks (Figure 1c). If shear occurred homogeneously throughout the whole shear zone, the shear zones would have a rectangular shape at a $\gamma=1$. The localization of strain along the slip zones preserves more substantial portions of the original sample geometry, which gives rise to the opposite shear sense appearance.

Upon closer look, slip zones can be identified as areas where a) unloading cracks concentrate, b) flow structures are evident, and c) no porosity is observable in a field emission SEM at high magnifications as documented in Figure 8. This slip zone microstructure is similar in all experiments, irrespective of the initial Qtz:Kfs ratio (Figure 9). Analyzing a slip zone SPO in detail using ACF tessellations as documented in Figure 10 shows a high anisotropy (b/a $\approx$ 0.4 ) and an orientation perpendicular to the shear zone boundaries within the slip zone for both Qtz and Kfs. The anisotropy of the ACF ellipses quickly increases to b/a $\approx 0.5-0.8$ outside of the slip zones with the orientation showing a large scatter.

Figure 11 summarizes our observations of the slip zones; at low strains, the slip zones occupy only a small portion of the sample $(1-2 \mathrm{vol} \%)$ and form short and straight segments (Fractal dimension, $D \approx 1.0$ ). With increasing strain, the slip zones become more volumetrically significant (up to $\approx 9 \mathrm{vol} \%$ ) and develop an anastomosing morphology (Fractal dimension, $D \approx 1.5$ ) as shown in Figures 7 and 11 and Table 2 . Kfs is systematically more abundant in the slip zones with respect to the rest of the sample, as presented in Figure 11c suggesting that the slip zones are depleted in Qtz.

No EBSD data could be obtained from the slip zones due to poor indexing of the phases. This is not surprising as it is almost impossible to resolve any grains within the slip zones from SEM-BSE images suggesting that extreme grain size reduction occurs within, as seen in Figures 8 and 9 .

The slip zones clearly accommodate significant strains and evolve with increasing finite strain. The material within the slip zones has accommodated more strain than the larger lenses of the fault rock. We will describe the microstructures of these lenses on the sample scale in further detail below. 


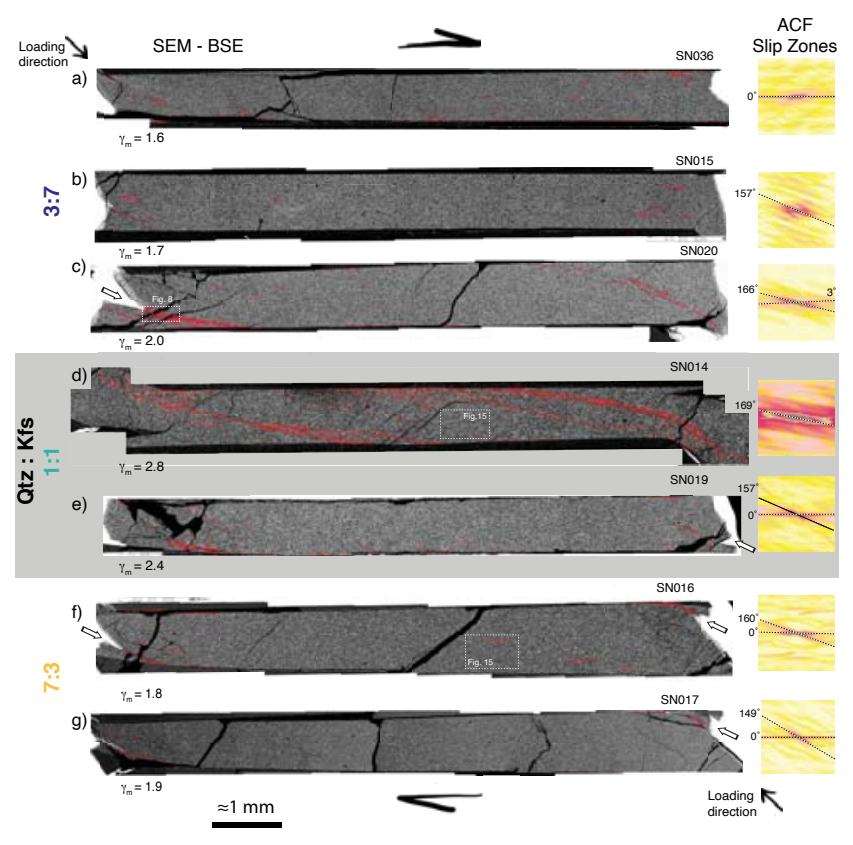

Figure 7. SEM-BSE images of deformed samples showing the slip zone geometry on the sample scale. a - c) 3:7, d-e) 1:1, f-g) 7:3 Qtz: Kfs ratio samples. Most of the slip zones originate at the boundaries of the shear zone and propagate inward with increasing strain. Experiments sheared to $\gamma>2$ have developed the most connected slip zones (high fractal dimension D). White arrows highlight the protrusion of the gold jacket (white) into the fault rock marking the presence of a slip zone. The average angle of propagation of the slip zones is estimated by measuring the dominant orientations of the ACF on the right. White dashed rectangles show location of high-magnification SEM images and EBSD maps shown in subsequent figures. 


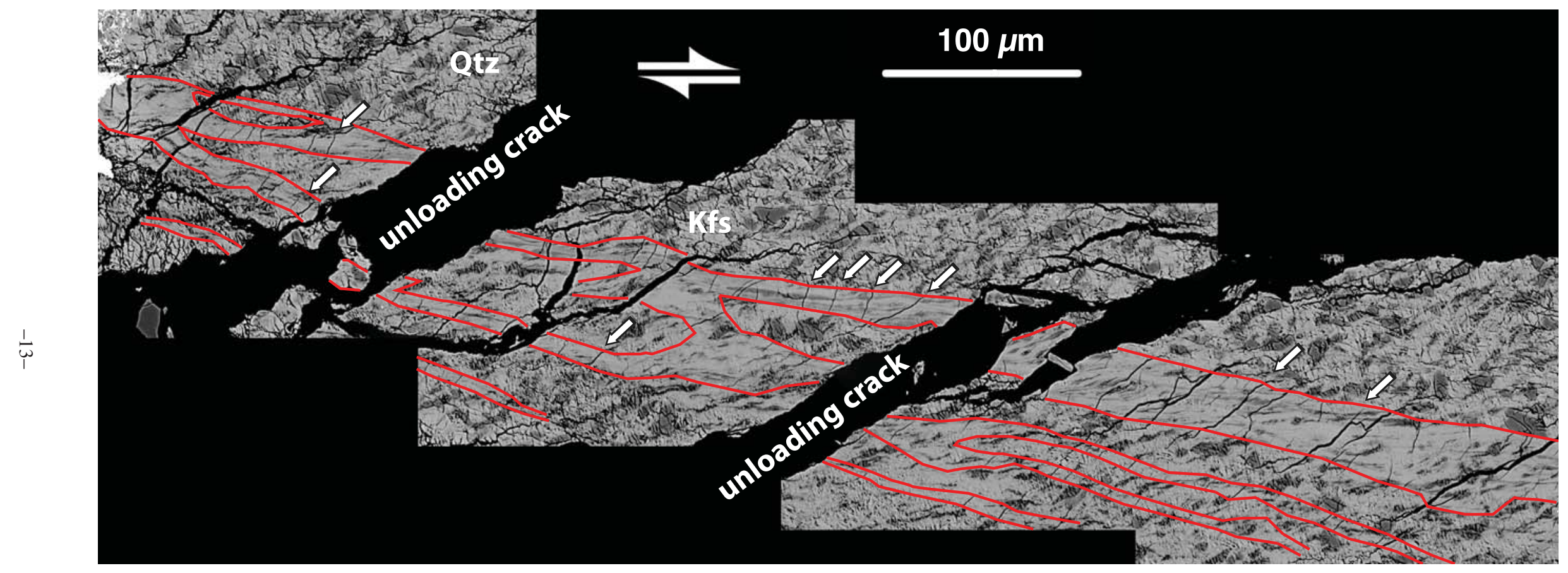

Figure 8. High-magnification image of a slip zone in a 3:7 Qtz:Kfs ratio sample (SN020). Image location within the sample shown in Figure 7. The slip zone is highlighted by red lines. White arrows highlight unloading cracks that concentrate in the slip zone material. Within the slip zone notice the flow-like patterns and no resolvable grains or porosity on the field emission SEM scale. 

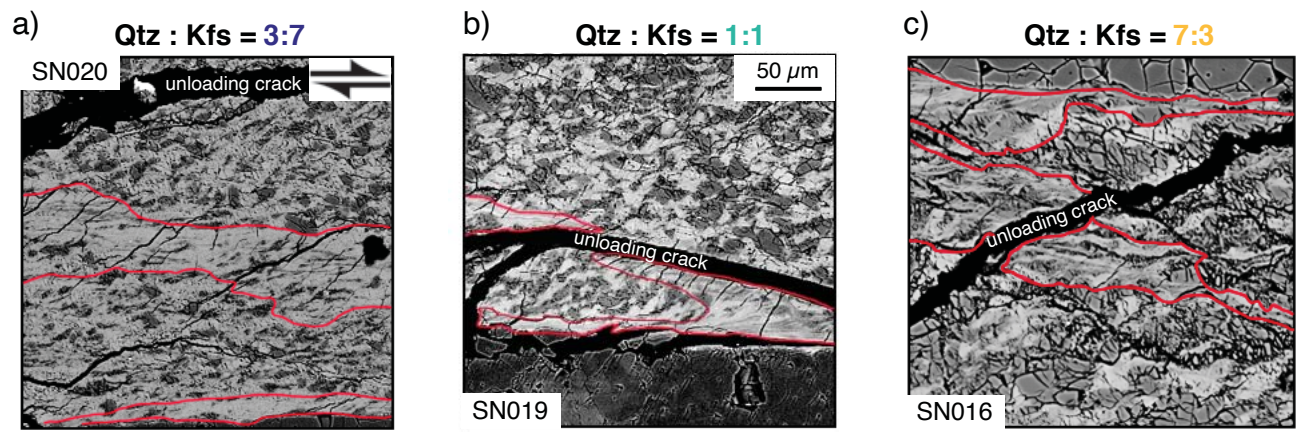

Figure 9. Representative slip zone microstructures from samples with different Qtz : Kfs ratios. Slip zones highlighted by red lines. 


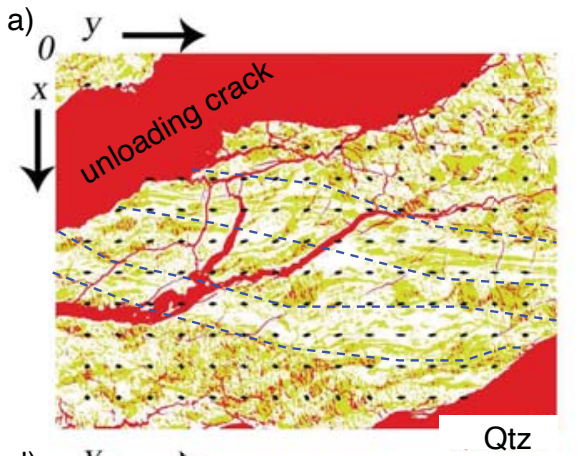

b)

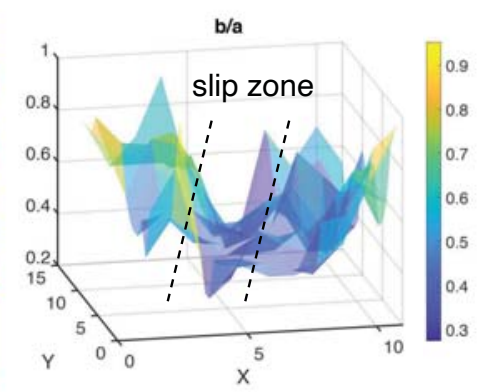

e)

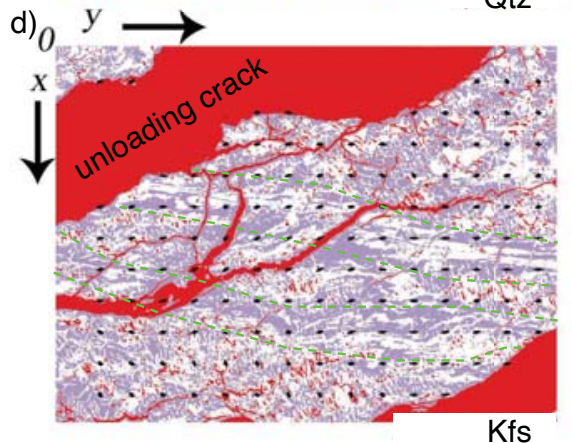

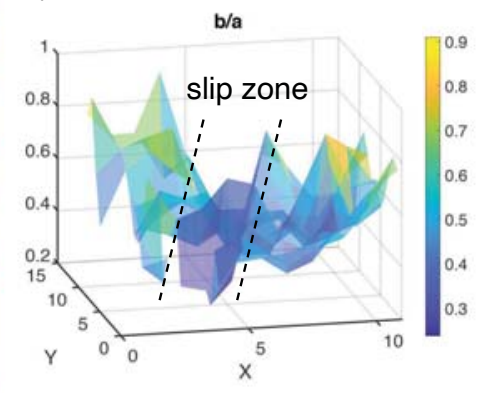

c)

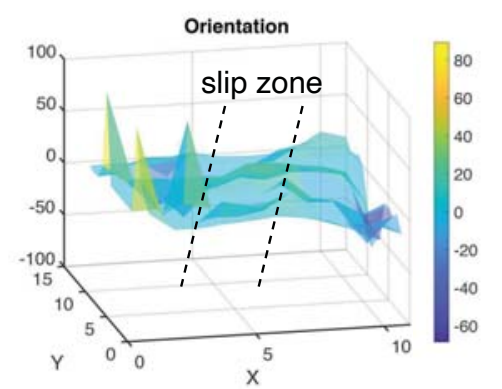

f)

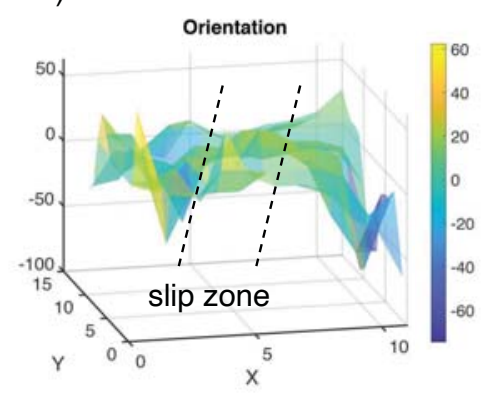

Figure 10. Tessellation of ACF squares surrounding a slip zone. a) \& d) ACF ellipses are plotted on the top of binary Qtz and Kfs images, respectively. Dashed lines highlight slip zones. Red background color represents unloading cracks. (b \& e) SPO anisotropy: axial ratio (b/a) of each phase plotted in a 3D plot. The slip zone has a higher anisotropy (lower b/a ratio) than the rest of the sample. (c \& f) ACF orientation. Inside the slip zones, the orientation is approximately zero (parallel to the shear zone boundary). 
a)

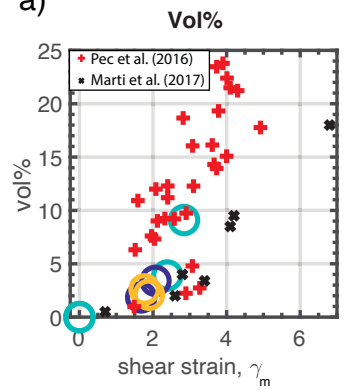

b)

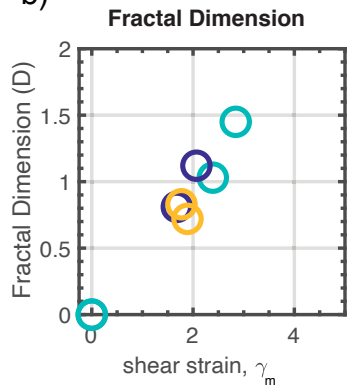

c)

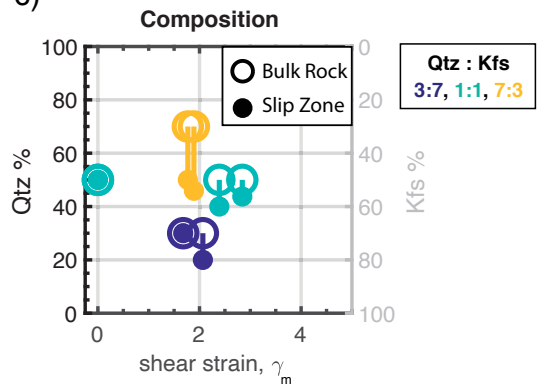

Figure 11. Summary of microstructural data from the slip zones. a) Volume of slip zones vs. shear strain shows a strong positive correlation. Red and black symbols show measurements from different studies performed at similar conditions, see text for details. b) Fractal dimension of slip zones: fractal dimension (i.e. complexity of the pattern) increases with increasing strain. c) Change in mineralogy within slip zones. In all samples, the slip zones are depleted in Qtz with respect to the bulk rock. Samples with an initial Qtz:Kfs ratio of 7:3 show the most significant change. 


\subsubsection{Fault Rock - Shear Zone Scale Observation}

Outside of the slip zones, the fault rock is pervasively fractured, and the individual mineral phases form elongated aggregates that define a weak foliation, as shown in Figure 12.

\subsubsection{Shape Preferred Orientation}

To assess the shape preferred orientation (SPO) of the individual mineral phases on the shear zone scale, we cropped $1 \mathrm{~mm}$ long sections $(\approx 10 \%$ of sample length) from the center of each sample's SEM image and produced binary images of Qtz and Kfs via grey-level thresholding for ACF analysis as shown in Figure 2. The result of the analysis for each mineral phase is presented in Figure 12 with the main results summarized in Table 2 and Figure 13.

Initial SPO prior to deformation was quantified from hot press experiments. Hot pressing at $800^{\circ} \mathrm{C}$ - where no melting was observed - shows a b/a ratio of $\approx 0.55$ for both minerals at an orientation of $\approx-10^{\circ}$ antithetic to the shear zone boundary. The b/a ratio in the experiment hot-pressed at $900^{\circ} \mathrm{C}$ - where minor melting is observed - is significantly lower ( $\mathrm{b} / \mathrm{a} \approx 0.48)$ and more sub-parallel to the shear zone boundary $\left(\approx-5^{\circ}\right)$. All deformed experiments were hot-pressed and deformed at $750^{\circ} \mathrm{C}$, so we assume that the initial fabric orientation and anisotropy are closer to the $800^{\circ} \mathrm{C}$ hot-pressed sample.

In deformed samples, Qtz is generally less anisotropic (i.e. higher b/a ratio) than Kfs, as documented in Figure 13a. With increasing strain, the anisotropy of both minerals slightly increases (b/a ratio decreases) and the SPO changes its angle from $\approx-10^{\circ}$ antithetic with the shear zone boundary up to $\approx 8^{\circ}$ synthetic with the shear zone boundary with the increasing strain.

To further investigate the variation of the SPO within a shear zone and SPO's evolution with increasing finite strain, we analyze a tessellation of 144 ACF squares. We use unsegmented SEM-BSE images of the deformed 1:1 Qtz:Kfs samples as shown in Figure 14. Each ACF ellipse is thresholded at $\approx 0.6 \%$ of the total area, and the square from which the ACF is derived is color-coded based on local ACF ellipse orientation to visualize the SPO variations on sample scale.

In the lower strain sample (Figure 14a), we observe a progressive change in ACF orientation from $5^{\circ}$ to $15^{\circ}$ (orange to green) on the left side of the sample to $0^{\circ}$ to $-10^{\circ}$ (red to purple) on the right side of the sample with a mode of $5^{\circ}$ for the whole shear zone. From the shape of the fault rock jacket interface, we infer that the left side has accommodated more strain than the right side of the sample suggesting inhomogeneous deformation. This observation is in agreement with the fact that slip zones are more developed on the left side of this sample as well. The rotation of the SPO from antithetic orientations at low strains to synthetic orientations at higher strains is in agreement with the data from all experiments presented in Figure 13. The fabric anisotropy of all ACF squares shows a relatively broad distribution with a mean of 0.43 and a standard deviation of 0.1 .

In the higher strain sample (Figure 14b), we observe a stronger SPO with a mode of $9^{\circ}$. Squares in the vicinity of slip zones generally show lower angles $\left(\approx 5^{\circ}\right.$, orange) than zones in between slip zones ( $>9^{\circ}$, green) in agreement with our higher magnification ACF analysis of the slip zones presented in Figure 10. The ACF orientation in the center of the sample is contaminated by unloading cracks, there the steepest orientation is observed $\left(25^{\circ}-30^{\circ}\right)$. Excluding this data, however, does not change the mode of the ACF orientation and makes the resulting SPO stronger with mode of $\approx 9^{\circ}$. The anisotropy of the fabric shows a narrower distribution compared to the lower strain sample, however, it has a similar mean, $\mathrm{b} / \mathrm{a} \approx 0.46$, and a standard deviation of 0.05 .

To summarize, our SPO measurements show that some strain is accommodated also in the cataclastic lenses. Qtz appears to deform less than Kfs under the studied conditions.

\subsubsection{Crystallographic Preferred Orientation}




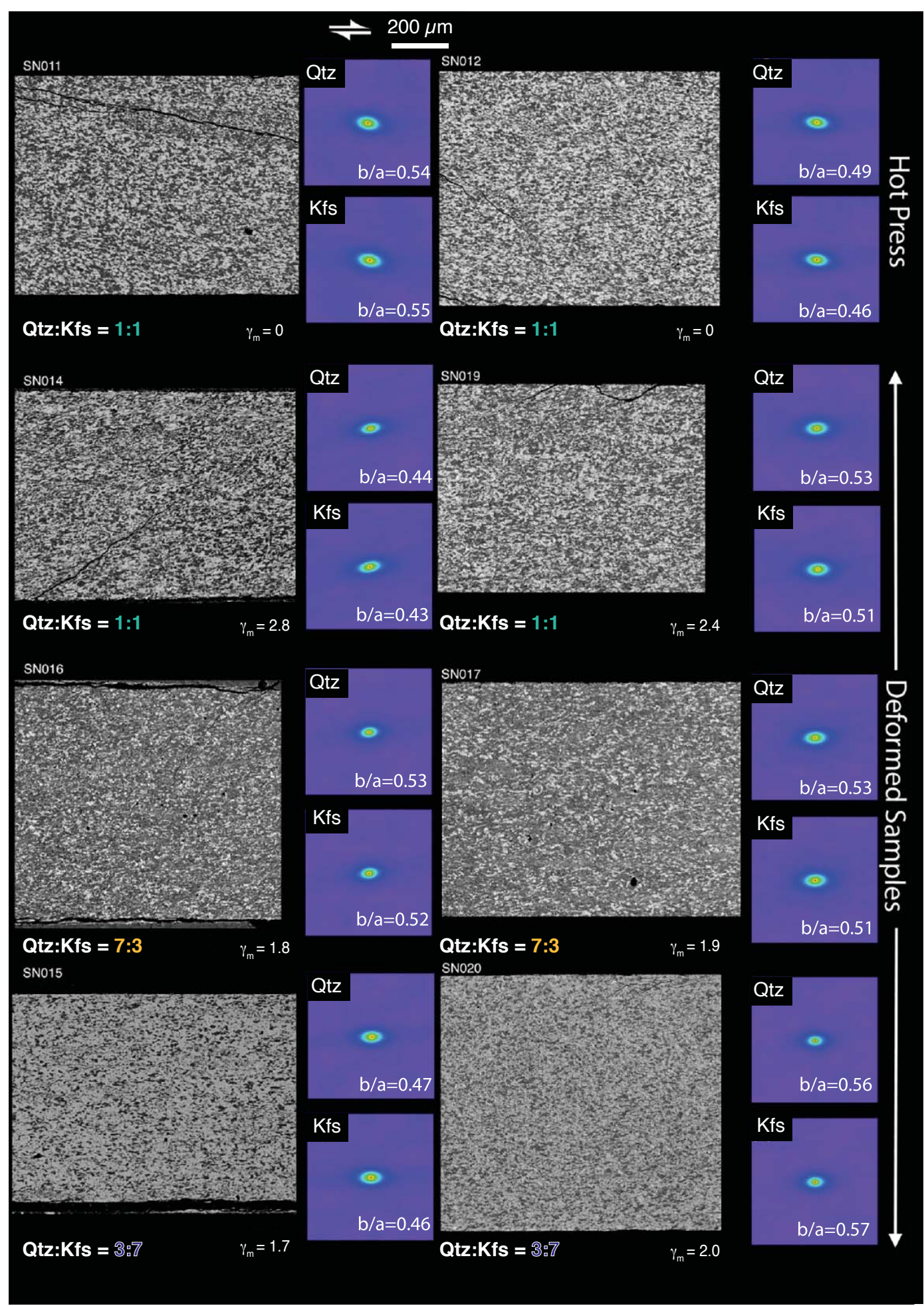

Figure 12. SEM-BSE images of the fault rock. Images are collected in the center of the shear zone (see Figure 2). The SEM-BSE images are segmented to obtain binary images with Qtz and Kfs. Insets show center of an ACF for each mineral. Measurements are reported in Figure 13 
a)

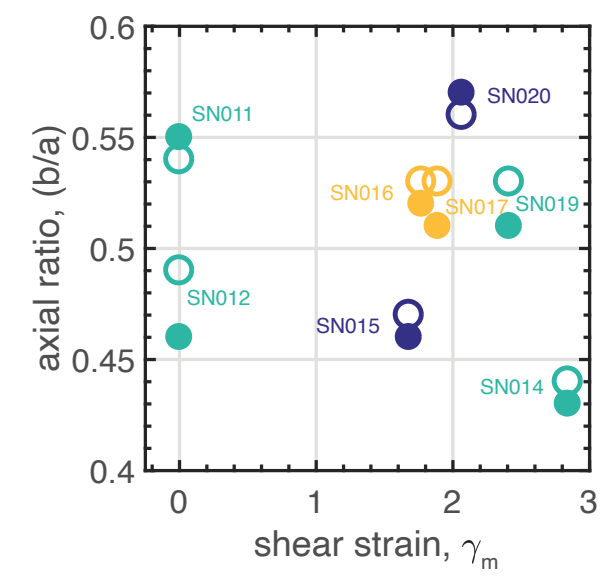

b)

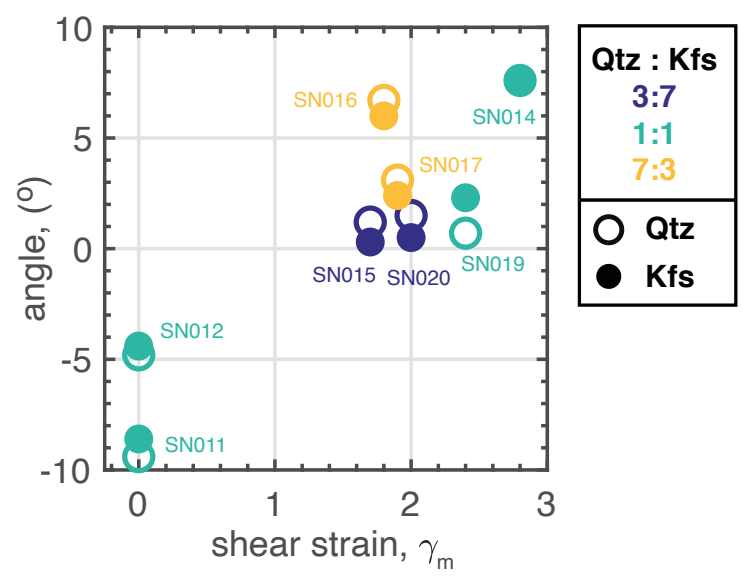

Figure 13. SPO data on the shear zone scale. a) Shear strain vs. ACF anisotropy b) Shear strain vs. orientation of ACF ellipses.

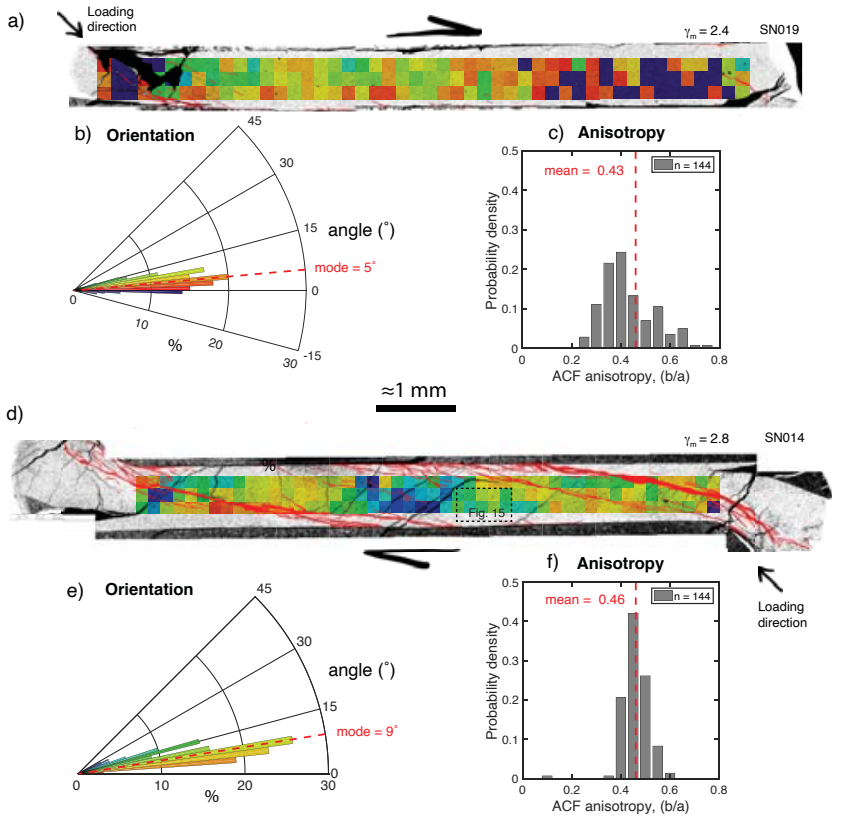

Figure 14. ACF tessellation analysis of 144 squares covering large portions of the shear zone from unsegmented SEM-BSE images in 1:1 Qtz:Kfs ratio samples. a) Constant-load sample b) ACF orientation rose diagram (colors in histogram correspond to colors of squares in a). c) ACF anisotropy histogram. d) Constant displacement rate sample, e) ACF orientation rose diagram (colors in histogram correspond to colors of squares in a). f) ACF anisotropy histogram. 


\begin{tabular}{|c|c|c|c|c|c|c|c|c|c|c|c|c|}
\hline \multirow[t]{2}{*}{ Sample } & \multirow[t]{2}{*}{ Qtz:Kfs } & \multirow[t]{2}{*}{$\gamma_{m}$} & \multirow[t]{2}{*}{ Thickness(mm) } & \multicolumn{2}{|c|}{ Axial Ratio(b/a) } & \multicolumn{2}{|c|}{$\operatorname{Angle}^{\circ}$} & \multirow[t]{2}{*}{ Bulk Porosity (\%) } & \multicolumn{4}{|c|}{ Slip Zones Analysis } \\
\hline & & & & Quartz & K-feldspar & Quartz & K-feldspar & & Average Slip Lengths $(\mu \mathrm{m})$ & Slip Area(\%) & Fractal Geometry (D) & Qtz:Kfs in slip zone \\
\hline SN011 & $1: 1$ & 0 & 0.86 & 0.54 & 0.55 & 9.4 & 8.6 & $5.5 \pm 0.5$ & $N / A$ & $N / A$ & $N / A$ & $N / A$ \\
\hline SN012 & $1: 1$ & 0 & 0.89 & 0.49 & 0.46 & 4.8 & 4.4 & $6.5 \pm 0.5$ & $N / A$ & $N / A$ & $N / A$ & N/A \\
\hline SN014 & $1: 1$ & 2.84 & 0.73 & 0.44 & 0.43 & 7.6 & 7.6 & $2.5 \pm 0.5$ & 2412 & 9.1 & 1.45 & $4.2: 5.8$ \\
\hline SN015 & $3: 7$ & 1.68 & 0.74 & 0.47 & 0.46 & 1.2 & 0.3 & $2.5 \pm 0.5$ & 207 & 1.85 & 0.81 & \\
\hline SN016 & $7: 3$ & 1.77 & 0.94 & 0.53 & 0.52 & 6.7 & 6 & $13 \pm 1$ & 603 & 2.6 & 0.83 & $1: 1$ \\
\hline SN017 & $7: 3$ & 1.89 & 0.83 & 0.53 & 0.51 & 3.1 & 2.4 & $12 \pm 1$ & 255 & 2.1 & 0.72 & $4.7: 5.3$ \\
\hline SN019 & $1: 1$ & 2.39 & 0.84 & 0.53 & 0.51 & 0.7 & 2.3 & $7.5 \pm 0.5$ & 509 & 3.9 & 1.03 & $4: 6$ \\
\hline SN020 & $3: 7$ & 2.07 & 0.84 & 0.56 & 0.57 & 1.5 & 0.5 & $13 \pm 1$ & 807 & 3.4 & 1.12 & $2: 8$ \\
\hline
\end{tabular}

Table 2. Summary of microstructural data.

To further constrain the active deformation mechanisms in our experiments, we performed EBSD (electron backscatter diffraction) analysis on two samples (SN014, 1:1 Qtz:Kfs ratio deformed to $\gamma \approx 2.8 \&$ SN016, 7:3 Qtz:Kfs ratio deformed to $\gamma \approx 1.8$ ). In the subsequent analysis, we focus on Qtz since Kfs indexes poorly in the maps. In Figures 15a \& 15d we color the grain orientations based on an inverse pole figure. No strong crystallographic preferred orientation (CPO) of the Qtz grains is observed in either of the samples as no color is dominant. In Figure 15b and 15e, we highlight Dauphiné twins by computing grain boundaries (defined by $>10^{\circ}$ misorientation) once using trigonal and once using hexagonal crystal symmetry. Dauphiné twins appear as grain boundaries when using trigonal symmetry as Dauphiné twinning involves a rotation of $60^{\circ}$ around [c] axis. However, Dauphiné twins are not visualized with a higher, hexagonal symmetry due to the fact that there is subsequently no difference between positive and negative $<a>$ axes (Kilian \& Heilbronner, 2017). Notice the high abundance of red boundaries, which highlight a rotation of $60^{\circ}$ around [c] axis, i.e. Dauphiné law. Also notice that the red grain boundaries have frequently complicated convoluted shapes as would be expected for penetration-type twins (Figure 15).

In Figure $15 \mathrm{c}$ and $15 \mathrm{f}$ we present pole figures computed using one data point per grain. The orientation distribution function (ODF) is calculated using an optimized de la Vallee Poussin kernel in MTEX. There is a clear CPO pattern in both analyzed samples to the poles of the positive $\{r\}$ and negative $\{\mathrm{z}\}$ rhomb planes, typical for Dauphiné twining (Rahle et al., 2018). The maxima and minima in poles to the $\{r\} \&\{\mathrm{z}\}$ rhombs, respectively, align consistently at higher angles than the macroscopic loading direction (shown by orange square in Figure 15). The lower strain sample shows a synthetic rotation of the $\{\mathrm{r}\}$ maxima (and complementary $\{\mathrm{z}\}$ minima) by $\approx 11^{\circ}$, and in the higher strain sample by $\approx 20^{\circ}$ (Figure $15 \mathrm{c} \& 15 \mathrm{f}$ ). Additionally, a very weak c-axis girdle pattern oriented $\approx 18^{\circ}$ to the shear zone boundary can be distinguished in the higher strain 1:1 Qtz:Kfs ratio sample. This orientation is very close to the local SPO observed by ACF analysis $\approx 15^{\circ}$ in the area where the EBSD was collected (see Figure 14). Further measurements on other samples would be needed to establish if this CPO pattern is meaningful given its very weak strength (maxima of 1.8 multiple random distribution). Lastly, we plot internal misorientation relative to the average orientation (mis2mean) within larger quartz grains in Figure 16. In general, the individual grains exhibit low misorientations suggesting little dislocation activity in agreement with the observed low pole figure strength. 
Qtz : Kfs $=1: 1, \gamma_{m} \approx 2.8$

(SN014)

Qtz : Kfs $=7: 3, \gamma_{\mathrm{m}} \approx 1.8$

(SN016)
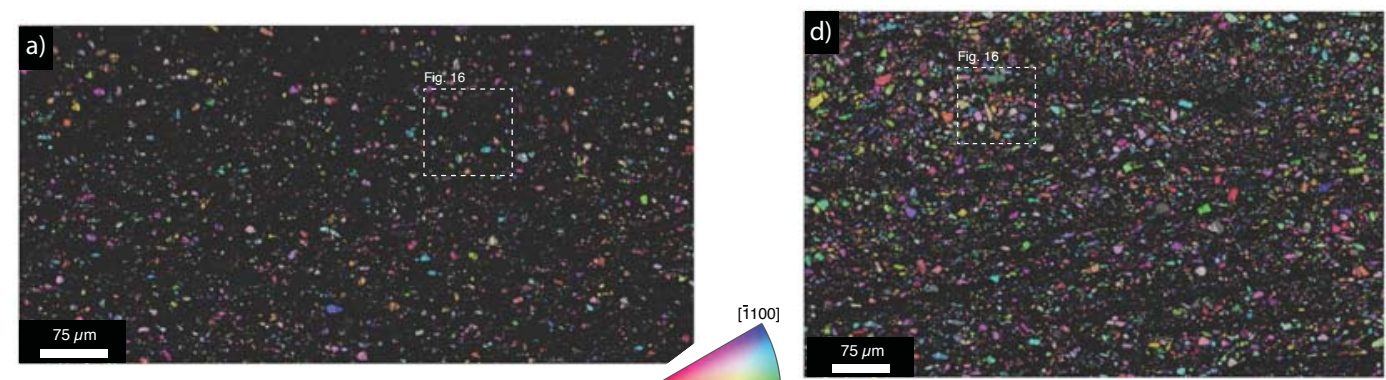

Dauphié twins

$[000$

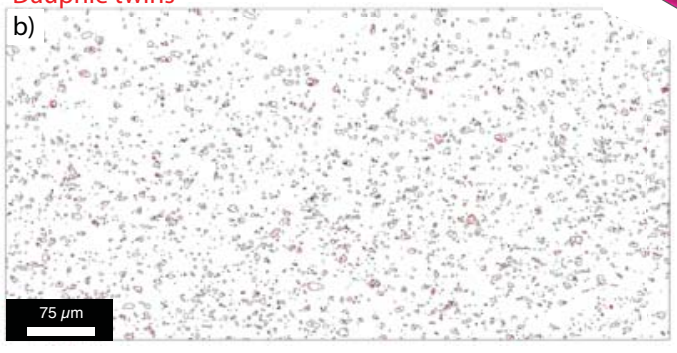

c)
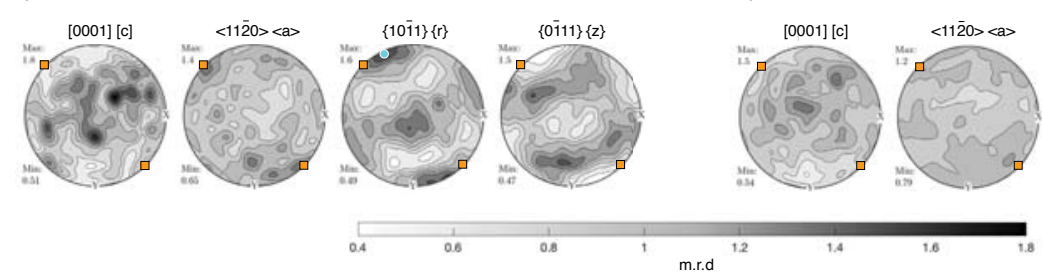

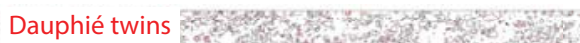

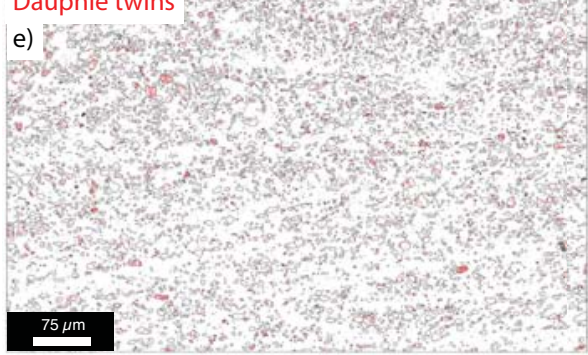

f)

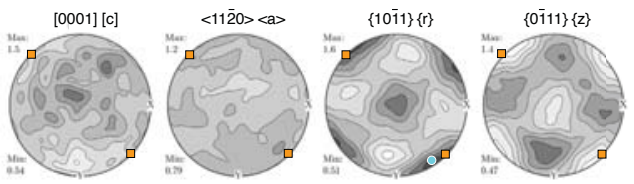

Figure 15. Summary of the EBSD analysis. a) \& d) Orientation map of the Qtz grains color coded by the inverse pole figure (inset). Band contrast image shown in the background. White dashed rectangles show position of high-magnification data shown in Figure 16. b) \& e) Dauphiné twin boundaries are shown in red. c) \& f) Pole figures. Orange squares represent the loading direction and the cyan circle highlights the $\{r\}$ axis maxima. Grain boundaries are in black.
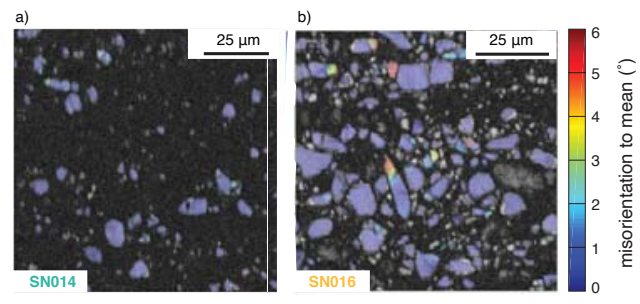

Figure 16. Misorientation with respect to mean orientation (mis2mean) within grains. Band contrast image as background. 


\section{Discussion}

In the following discussion, we first estimate dominant length-scales of strain localization and strain partitioning on the sample scale. Second, we infer local stress orientation in general shear experiments based on EBSD data and discuss the influence of localization and mineral ratio on sample strength. Third, we identify the active deformation mechanisms accommodating strain in our samples and consider the physical processes responsible for the development of slip zones and partially amorphous materials within. Finally, we discuss rheological models that could appropriately describe bi-mineralic rocks deforming in the semi-brittle flow regime .

\subsection{Strain Localization and Partitioning}

All deformed samples show the development of localized slip zones on length-scales much longer than the grain size. These zones are depleted in Qtz (Figures $9 \& 11$ ) and better developed in samples with higher Kfs content (Figure 7). The volume occupied by these slip zones and their geometric complexity increases with increasing strain (Figure 11) suggesting that while the material in the slip zones is weaker than the surrounding fault rock, for deformation to proceed more and more slip zones are needed to accommodate the imposed strain. From the strong SPO contrasts between slip zones and their surrounding (Figures 10 and 14), we infer that the viscosity of the slip zones must be significantly lower than the viscosity of the surrounding fault rock. At highest explored strains, a network of anastomosing branches cross-cuts the shear zone and surrounds coarser grained lenses over a range of length-scales (tens of microns to millimeters, Figure 7d).

These lenses also accommodate strain as seen in the SPO measurements (Figures 13 and 14) and form geometric obstacles that have to move past each other during deformation. On the grain-scale, Qtz is the stronger mineral at our experimental conditions as it shows lower anisotropy (higher b/a) than Kfs irrespective of the exact mineral ratio (Figure 12). However, the differences between the anisotropy of the two phases are rather minor suggesting that the viscosity contrasts on the grain scale are negligible compared to the viscosity contrasts between the slip zones and the coarser-grained lenses formed of the Qtz:Kfs aggregates.

\subsection{Stress Orientation in General Shear Experiments}

Dauphiné twinning, while not accommodating any strain $\left(60^{\circ}\right.$ rotation around [c] axis), produces a crystallographic preferred orientation (CPO) that can be useful for tracking the $\sigma_{1}$ direction (Tullis, 1970; Menegon et al., 2011; Kilian \& Heilbronner, 2017; Rahl et al., 2018). Qtz is elastically stiffer around the negative rhomb $\{z\}$ direction and Dauphiné twinning aligns the more compliant positive rhomb $\{\mathrm{r}\}$ direction parallel to $\sigma_{1}$ to maximize the strain energy of the system (Tullis, 1970). It is interesting to note that the inferred $\sigma_{1}$ direction based on Dauphiné twinning is significantly different - up to $20^{\circ}$ rotated synthetically at $\gamma_{m} \approx 2.8$ than the loading direction which is commonly referred to as the " $\sigma_{1}$ " direction in rock mechanics (Figure 15). This rotation is expected in a transpressive deformation regime (i.e. combination of pure and simple shear deformation (see discussion in Fossen \& Tikoff, 1993 and Heilbronner \& Kilian, 2017). Consequently, the slip zones do not form close to an orientation that would be expected for dilatant, brittle failure $\left(\approx 35^{\circ}\right.$ relative to $\left.\sigma_{1}\right)$ but are oriented at a much flatter angle $\left(\approx 55^{\circ}\right.$ relative to $\left.\sigma_{1}\right)$ and hence have a larger normal stress component acting on the slip plane (Figure 7). This observation further implies that the material in the slip zones is non-dilatant and weak. Clearly, a more complete understanding of the stress state during general shear experiments is needed.

\subsection{Influence of Composition and Strain Localization on Aggregate Strength}

The strength of the samples is dependent on the volume proportion of the constituent minerals in a non-trivial manner. Samples with Qtz:Kfs $=1: 1$ ratio reached the highest strength, 
while samples with Qtz:Kfs $=3: 7$ ratio are the weakest and samples with $7: 3$ ratio of Qtz to Kfs reached intermediate peak shear stress. As discussed above, the strength of the rocks is likely controlled by the development of slip zones. The slip zones reach a percolation threshold throughout the sample at peak shear stress and their topology clearly is reflected in the mechanical data: samples that have high fractal dimension (D) and dominant slip zone orientation oblique to the shear zone boundary (orientation of $160^{\circ}-170^{\circ}$ ), show a prolonged change from strengthening to weakening around peak strength (e.g SN014, Figures $3 \mathrm{~b}$ and 7d). On the contrary, in samples with low D and well developed shear zone parallel slip zones (orientation of $0^{\circ}$, e.g. SN017, Figures $3 \mathrm{c}$ and $7 \mathrm{~g}$ ), we observe a more abrupt change from strengthening to weakening behavior and concomitant larger increase in $\sigma_{1}$ displacement rate, suggesting that once a kinematically favorable failure plane develops, the rocks lose their load bearing capability (Pec et al., 2016). Nevertheless, the failure does not manifest itself as a "stickslip event", i.e. abrupt stress drop accompanied by rapid displacement jump as commonly observed during deformation at lower temperatures and thought of as an analogue to an earthquake, but more as a 'slow slip event' where a transient increase in displacement rate is followed by deceleration (Figure 3) suggesting that the slip zone material is rate-strengthening and stabilizes fault slip. This observation however has to be interpreted with care as the stability of faults depends both on the material properties as well as the stiffness of the loading system (e.g. Burdette \& Hirth, 2018). Further detailed characterization of the complex stiffness of our hydraulically driven apparatus is needed to corroborate this conclusion.

\subsection{Nature of Slip Zone Material}

Typical microstructures within slip zones display flow-like patterns with no visible porosity (Figure 8) and high fabric anisotropy (low b/a ratios, Figure 10) suggesting that the material deforms as a continuous, non-dilatant, viscous fluid. The fact that unloading cracks concentrate in the slip zones suggests that the zones are cohesive, permanently deformed and store less elastic energy than the surrounding fault rock. Upon unloading to room conditions this stored elastic energy budinages the permanently deformed material in the slip zones and leads to the development of the localized unloading cracks (Fitz Gerald et al., 1991; Stünitz et al., 2003; Pec et al., 2012). On the SEM scale, the microstructures within slip zones in this study are strikingly similar to the nano-crystalline, partially amorphous material (PAM) developed in slip zones of Pec et al., 2012a,2012b, 2016 and Marti et al., 2017, 2020 (compare for example Figure 8 to Figure13a from Pec et al., 2016). On the TEM scale, PAM was formed of nanometric, extremely fine-grained clasts (mean grain size of $30-300 \mathrm{~nm}$ ) surrounded by a TEM-amorphous matrix (Pec et al., 2012b, 2016; Marti et al., 2017, 2020). PAM was primarily formed of feldspars suggesting that feldspars are susceptible to this microstructural transformation from a crystalline solid to a nanocrystalline to amorphous material.

While we lack observations on the TEM scale in this study, we infer that the slip zones in our experiments are formed of a similar material as PAM. It is worth noting that no material that would resemble fully amorphous material (AM) from Pec et al., 2012b was observed in our experiments suggesting that either the increased temperature and concomitant lower stresses, or lack of micas inhibited the formation of AM under the here studied conditions.

\subsection{Active Deformation Mechanisms}

The dominant deformation mechanism by volume is cataclastic flow as pervasive fracturing is observed on the sample scale. Fracturing produces fine grain sizes that are a pre-cursor to the development of PAM (e.g. Pec et al., 2016). Most strain is accommodated in thin slip zones composed of PAM that show microstructures indicative of viscous flow as discussed above. We infer the deformation mechanisms operating in PAM are a combination of diffusion creep (due to extremely small grain sizes) and viscous flow of the amorphous material. Amorphous solids are thought to deform by 'shear transformation zones' where localized displacement of atoms acts as an agent of deformation (Falk \& Langer, 2011). The PAM can possibly be con- 
ceptualized as a polycrystalline material with an (rather substantial) amorphous layer surrounding the grain boundaries.

The exact rheology of PAM however is currently unknown as the measured mechanical data in our as well as previous experiments (e.g. Pec et al., 2016, Marti et al., 2020) capture the combination of both viscous flow in PAM as well as fracturing in the cataclastic lenses. Both cataclasis, as well as viscous flow operate in parallel to accommodate the imposed strain as discussed above. Based on the 'slow slip' like behavior upon weakening, we inferred that PAM is rate-strengthening which would certainly be true for a linear-viscous fluid. However, extrapolating deformation mechanisms operative in micro-crystalline materials into the nanocrystalline realm has a potential for large errors. Micro-crystalline materials are volume-dominated whereas nano-crystalline materials are surface dominated and consequently the mechanical properties can vary substantially (e.g. Meyers et al., 2006). Amorphous solids lack any long range order and hence grain boundaries and consequently, their mechanical properties are distinct from crystalline solids (e.g. Schuh et al., 2007 ). Direct measurements of PAM rheology are therefore needed.

\subsection{Origin of Nanocrystalline, Partly Amorphous Materials in Experiments}

Nanocrystalline to amorphous materials have been increasingly frequently identified within zones of strain localization in experiments on felsic, feldspar-rich rocks such as granitoids (Yund et al., 1990; Pec et al., 2012; Pec et al., 2012; Pec et al., 2016; Hadizadeh et al., 2015) and mafic, feldspar-rich rocks such as diabase and gabbro (Weiss \& Wenk, 1983; Marti et al., 2017, 2020). While feldspars seem to be especially prone to amorphization, nanocrystalline to amorphous material has also been documented in experiments on quartzites (Goldsby \& Tullis, 2002; Di Toro et al., 2004; Toy et al., 2015 ; Hayward et al. 2016; Rowe et al. 2019), in clay minerals (Aretusini et al., 2017; Kaneki et al., 2020) and even carbonates (Verberne et al., 2013, 2014, 2017; Delle Piane et al., 2018) suggesting that comminution to nanometric grain sizes and concomitant amorphization is prevalent during experimental rock deformation.

To further constrain the conditions favorable for PAM formation in feldspar-rich rocks, we compiled available literature data in Figure 17. The volume of the slip zones in our experiments is in good agreement with the measurements by Marti et al., (2017 and 2020) who deformed mafic rocks (Maryland Diabase, Plagioclase content $\approx 57 \mathrm{vol} \%$ ) at $P_{c}=0.5-1.5$ $\mathrm{GPa}$ and $\mathrm{T}=300-800^{\circ} \mathrm{C}$ (Figure 11). The amount of PAM is generally higher in granitoid rocks of Pec et al., (2016) (Verzasca gneiss, Plagioclase + Kfs content $\approx 61 \mathrm{vol} \%$ ) deformed at $P_{c}=0.3-1.5 \mathrm{GPa}$ and $\mathrm{T}=300-600^{\circ} \mathrm{C}$. These granitoid rocks contain $\approx 2 \mathrm{vol} \%$ of micas, suggesting that water content or presence of phyllosilicates may play a role in the abundance of PAM.

The most obvious trend in the data in Figure 17a and 17b is the increase in slip zone volume with increasing strain: the earliest any PAM material is observed is at a shear strain of $\approx 1$, after which the volume occupied by slip zones increases monotonically up to $\approx 25 \mathrm{vol} \%$ of the fault rock. Second, high peak shear stresses seem to favor the development of PAM as shown in Figure 17a. The dependence of PAM abundance on temperature seems more complicated when plotted against strain (Figure 17b) - most of the experiments presented in Figure 17 were performed under constant displacement rate boundary conditions, temperature and peak shear stress therefore do not vary independently (i.e. hotter experiments reach lower peak shear stresses).

To incorporate frictional experiments performed at much lower stresses to much higher strains (Yund et al., 1990), we plot the volume of slip zones as a function of strain energy density (stress $\mathrm{x}$ strain) and normalize the experimental temperature to the melting temperature of the bulk rock (granite $=650^{\circ} \mathrm{C}$, diabase $=1050^{\circ} \mathrm{C}$, Qtz:Kfs $=900^{\circ} \mathrm{C}$ ) in Figure 17c. We observe that the work done on the sample together with the homologous temperature control the PAM volume: PAM formation is clearly favored by inputs of both mechanical as well as thermal energy. 
To conclude this section, PAM seems to form readily in rocks containing feldspars over a broad range of temperature - pressure and strain-stress space. The controlling variable for PAM production is likely the work input (i.e. stress $x$ strain per unit volume) into the rocks as PAM forms both at high stresses and low strains (Pec et al., 2016; Marti et al., 2020) as well as at low stresses and high strains (Yund et al., 1990; Hazidadeh et al., 2015; Kaneki et al., 2017). PAM formation is further favored by elevated temperatures. The abundant observation of nanocrystalline to amorphous materials in fault rocks questions the concept of a 'grinding limit', i.e. a minimum grain size after which further grain size reduction should not occur (e.g. Sammis \& Ben-Zion, 2008): apparently no such limit exists as grains can be reduced down to unit cell sizes where the concept of a grain with long range crystalline order loses meaning.

\subsection{Mechanisms of Partially Amorphous Material Formation}

What is the mechanism of PAM formation? In general, amorphous materials can be produced either by solid-state amorphization or by melting (e.g. Wolf et al., 1990). Microstructural observations in experiments containing PAM lack clear evidence of high temperatures such as euhedral crystals or fast quench temperatures such as dendritic crystal growth, (Yund et al., 1990; Pec et al., 2012, 2016; Hazidadeh et al., 2015 and Marti et al., 2020). These observations together with mechanical data (shearing at sub-seismic velocities) all point towards the conclusion that the PAM forms by a solid-state amorphization process and hence is distinct from high velocity friction melts.

Numerous mechanisms of solid-state amorphization exist. For the typical experimental conditions, we expect two to be important: a) Pressure-induced amorphization which is observed upon static as well as dynamic compression in a number of minerals. This mechanism requires a negative volume change and occurs when a denser amorphous phase is accessible to the system. Qtz amorphisizes by pressures of $10-30 \mathrm{GPa}$ and feldspars by $16-28 \mathrm{GPa}$ under isostatic conditions at room temperature (see Richet and Gilet, 1997 and Machon et al., 2014 for reviews). Both are ranges significantly above measured far field stresses and pressures in experiments. However, shearing, elevated temperatures, and presence of grain to grain contacts and related stress concentrations - all abundant in rock deformation experiments - is known to lower the amorphization pressure (e.g. Machon et al., 2014; Sims et al., 2019). Onset of amorphization in feldspars was observed at pressures as low as 2 - 9 GPa (Daniel et al., 1997) rendering pressure-induced amorphization as a possible mechanism for PAM formation. If that is the case, PAM should have a higher density than crystalline Kfs from which it is mostly derived. Another possible mechanism for PAM formation is by b) mechanical wear induced amorphization. Grinding and high-energy milling yields amorphous materials via introduction of high defect densities (e.g. Fecht et al., 1999; Sanchez et al., 2004; Nojiri et al., 2013, see Suryanarayana, 2001 for review). Such amorphous phases typically have lower densities than their crystalline protoliths (Nojiri et al., 2013) and hence could be distinguished from pressureinduced amorphous materials if density measurements of PAM could be obtained. Both pressureinduced amorphization as well as mechanical wear induced amorphization can produce microstructures with amorphous regions surrounding crystalline clasts much like observed in PAM (e.g Yund et al. 1990; Pec et al., 2016; Marti et al., 2020) and therefore we suggest that PAM forms by a combination of these two processes.

\subsubsection{PAM Formation, Ultimate Strength of Rocks and Self-localized Thermal Runaway}

How strong can a rock get and what mechanisms allow it to eventually fail? At experimental strain rates, the elevated pressures $(0.3-1.5 \mathrm{GPa})$ and low to moderate temperatures $\left(\mathrm{T}=300-800^{\circ} \mathrm{C}\right)$, inevitably lead to high differential stresses: the high pressure hinders crack opening and motion, and low temperatures and short timescales hinder diffusion and dislocation motion. Phase boundaries in poly-phase materials further pose barriers to dislocation glide that typically limits strength of monomineralic materials at HP-LT conditions (e.g. Kumamoto et al., 2017) restricting the means by which a rock can accommodate strain. 
One mechanism that was suggested as capping the strength of rocks at high stresses is self-localized thermal runaway (i.e Braeck et al., 2006; Kelemen \& Hirth, 2007). This mechanism hinges on a feedback between temperature and viscosity: localized shearing leads to local temperature increase which lowers the viscosity and so can lead to a run-away effect. Could this mechanism be operating in our experiments?

Our measurements of sample temperature as well as furnace output during the rapid acceleration of strain rate at the end of constant load experiments do not indicate any abrupt temperature increase (Figures $6 \mathrm{~b}$ and $6 \mathrm{~d}$ ). If the sample was generating significant heat, we would expect to see a $\mathrm{T}$ increase and/or a concomitant furnace power decrease. However a caveat to keep in mind is that rapid sample deformation can lead to movement of the thermocouple and furnace deformation (see Figure 1) that could potentially obscure a $\mathrm{T}$ increase related to shear heating.

To further constrain the temperature evolution during shearing, we constructed a finite volume model for a simulation of the heat flow within a cube of the sample size under the experimental conditions. We take the mechanical data from constant load experiments as input and calculate two solutions for two localization extremes: one where all deformation occurs throughout the sample homogenously, and second where all straining is localized in $1 \%$ of sample volume. As shown in Figure 18, there is no significant increase in temperature $\left(<10^{\circ} \mathrm{C}\right)$ due to shearing in either case (see the Appendix for details of the simulation). It therefore appears that shear heating and associate viscosity decrease is of subordinate importance in PAM formation and the weakening of rocks at our experimental conditions.

\subsection{Rheological Models of Parallel Semi-brittle Flow}

To summarize our observations so far, it appears that the mechanical and microstructural data are well explained with localization of strain into viscous slip zones. The viscous component stabilizes fault slip and is responsible for the "slow-slip" like nature of weakening. Larger lenses delimited by slip zones have to slide past each other and likely control the stress, at least at low strains. Intense comminution leads to a microstructural transformation from a crystalline solid to an amorphous fluid-like material at stress concentrators. This amorphous material is significantly less viscous than its precursory micro-crystalline material and has a different activation energy, $\mathrm{Q}$, and stress dependence, $n$ (assuming a constitutive equation $\dot{\epsilon}=\sigma^{n} e^{-Q / R T}$ ) and possibly different density, $\rho$.

Neglecting elastic contributions, two-mechanism rheological models that couple in parallel a frictional slider with a (non-linear) dashpot element are most appropriate for describing our experimental observations. In other words rocks in semi-brittle flow regime can be approximated as Bingham solids, i.e. a yield strength has to be reached before the rocks flow viscously. Furthermore, strain is clearly an important variable that cannot be neglected: the rocks have to shear to a $\gamma_{m} \approx 1$ to produce PAM that introduces the viscous element.

There are models available considering such rheology from the grain scale to the outcrop scale. Beall et al., (2019) developed a rheological model motivated by geological observations of subduction zone mélanges (Fagereng \& Sibson, 2010; Rowe et al., 2013; Phillips et al., 2020). The model consists of a linear viscous matrix and brittle lenses of various size distributions up to tens of meters. The jamming of individual lenses leads to stress build up followed by fast slip or creep periods once a jamming event is overcome. A conceptually similar micro-mechanical model on the grain-scale was developed in the Utrecht laboratory (Bos \& Spiers, 2002; Niemeijer \& Spiers, 2007; Verbene et al., 2020) for frictional-viscous flow of bi-mineralic rocks containing phyllosilicates where the rate-limiting step is fluid mediated diffusion in a stress gradient. If the detailed rheology of PAM material would be known, these models could be adapted to the here described semi-brittle flow of felsic rocks. 

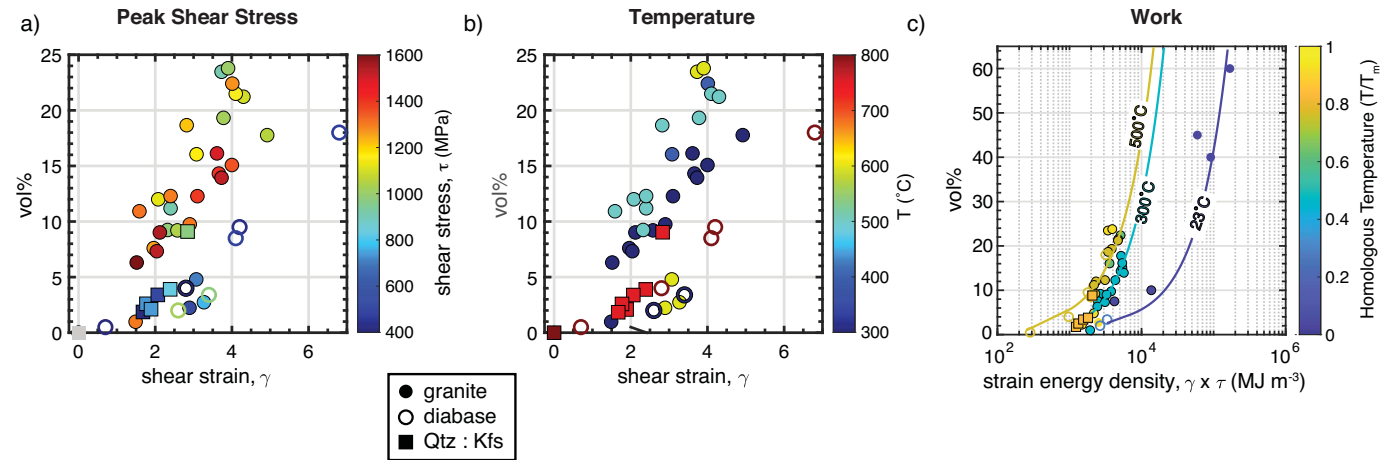

Figure 17. The volume of the slip zones from our experiments with the data from Pec et al., 2012, 2016 \& Marti et al,. 2017, 2020 and Yund et al., 1990. color coded for different conditions. Solid circles are for granitic rocks, empty circles are for diabase and squares for Qtz:Kfs aggregates. a) Shows the effect of peak shear stress on the vol\% of the slip zones. b) The effect of temperature on the vol\%. c) Illustrates the effect the strain energy density on the vol\% of slip zones normalized to homologous temperature. Curves show the least squares fits to the granite data.

\section{Conclusion}

We performed general shear experiments using a Griggs-type apparatus over various quartz and K-feldspar mineral ratios. Based on the analyzed mechanical and microstructural data we conclude that:

- The main deformation mechanisms by volume are cataclasitic flow and Dauphiné twinning. Most strain, however, is accommodated in localized slip zones formed of partially amorphous material.

- The partially amorphous material forms due to comminution and grain size reduction down to the nanometer scale. Mechanical wear induced amorphization and/or pressure induced amorphization are the likely physical process leading to the microstructural transformation from crystalline solid to an amorphous fluid-like material in experiments.

- Partially amorphous materials form in a number of lithologies and under a broad range of conditions in experiments. Their abundance is controlled to the first order by the input of mechanical work per volume and homologous temperature.

- The inferred deformation mechanism accommodating strain in the slip zones is a combination of diffusion creep and viscous flow. Partially amorphous materials introduce a viscous element into the behavior of fault rocks and stabilize fault slip under the studied conditions.

- Weakening occurs once the partially amorphous material percolates through the sample. The abundance and geometry of the partially amorphous material controls sample strength.

- Both cataclastic faulting as well as viscous flow in slip zones have to operate in parallel to accommodate the imposed strain. This semi-brittle flow of polymineralic rocks can be modeled by a frictional-viscous rheology where a frictional slider is coupled in parallel with a (possibly non-linear) viscous element.

\section{Acknowledgments}

We would like to thank Hamed Ghaffari for assistance with experiments, Rüdiger Kilian and Andy Cross for useful tips on EBSD data processing and interpretation, Pascal Tschudin for making great thin section. We also would like to thank Holger Stunitz and Kai Neufeld 
for EBSD imaging. Funding for the CORD laboratory technician support from NSF \# 1833478 is gratefully acknowledged. The data that support the findings of this study are openly available in Zenodo (https://doi.org/10.5281/zenodo.4130851), Pec and Al Nasser (2020). 


\section{Appendix}

\subsection{Strain Heating Simulation Results}

As the samples deform, internal heat is generated as a result of mechanical work. Numerical simulation of the heat flow equation is solved to constrain the heat generation due to straining. This analysis will enable us to understand any rise in temperature or change in furnace power. The heat flow equation (Eq 1) is solved by implementing a finite volume method on a discretized grid accounting for thermal diffusivity, heat capacity, material density and strain rate. The definition and value of symbols are in Table3.

$$
\rho C \frac{\partial T}{\partial t}=\nabla(\rho C D \nabla T)+Q_{s h}
$$

\begin{tabular}{lccc}
\hline Symbol & Definition & Qtz value & Kfs value \\
\hline$\rho$ & density $\left(\mathrm{kg} / \mathrm{m}^{3}\right)$ & 2320 & 2560 \\
$C$ & heat capacity $(\mathrm{J} / \mathrm{kg} / \mathrm{C})$ & 1166 & 1570 \\
$D$ & thermal diffusivity $\left(\mathrm{m}^{2} / \mathrm{s}\right)$ & $6.2 \times 10^{-} 7$ & $3.7 \times 10^{-} 7$ \\
$T$ & temperature $(\mathrm{C})$ & & \\
$Q_{s h}$ & strain heating $\left(\mathrm{W} / \mathrm{m}^{3}\right)$ & & \\
$t$ & time (s) & &
\end{tabular}

Table 3. Typical thermal parameters for Qtz and $\mathrm{Kfs}$ at $T=750^{\circ} \mathrm{C}$ used for the heat flow simulation.

Using the values in Table 3 on a discretized cubical grid of the same size as the original sample, we can predict how much temperature is increased as a result of straining the sample. We chose the Dirichlet boundary condition $T=750^{\circ} \mathrm{C}$ across all faces of the cube. The initial conditions are set $T=750^{\circ} \mathrm{C}$ also. At each time step of the simulation, the strain heating is completed based on (Eq 2).

$$
Q_{s h}=\tau \dot{\gamma}
$$

We simulated the heat flow based on the constant load experiment SN019. Two different simulation results were examined. In Figure 18(a), we demonstrate the temperature change as a result of the mechanical deformation. The sharp increase in temperature is correlated with the fast strain rate toward the end of the experiment. In Figure 18(b), we have run the same simulation except that a slip zone, occupying $\approx 4 \%$ was introducing as a high strain rate zone. Here, the slip zone's strain rate was chosen to be three orders of magnitude higher than the bulk strain. Both simulation results do not indicate a substantial increase in temperature.

The simulation suggests the it would be difficult to measure such small $\mathrm{T}$ increases in experiments, as suggested by data in Figure 6. By extension, temperature induced processes are of secondary importance in these experiments. The crystalline of amorphous transition in slip zone material introduces a new viscous element causing semi-brittle behavior. 
Heat Flow Simulation Without Slip Zone Development

a)
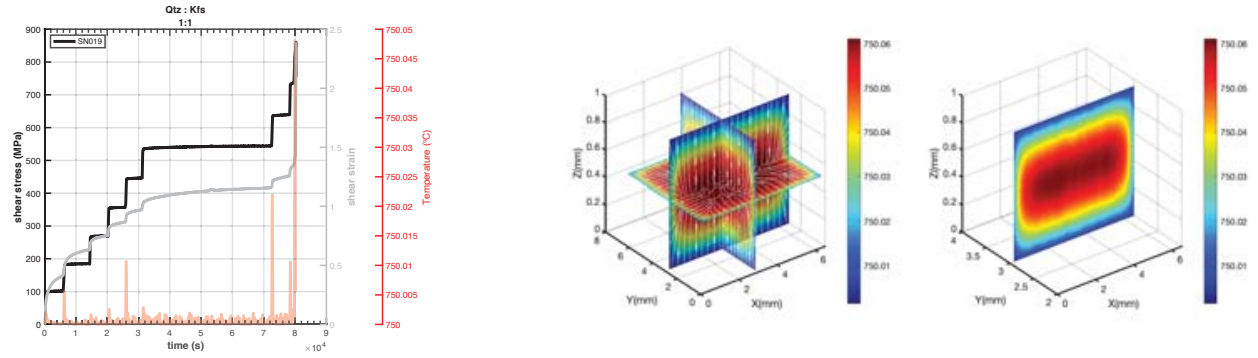

Heat Flow Simulation With Slip Zone Development

ar: : : Kts

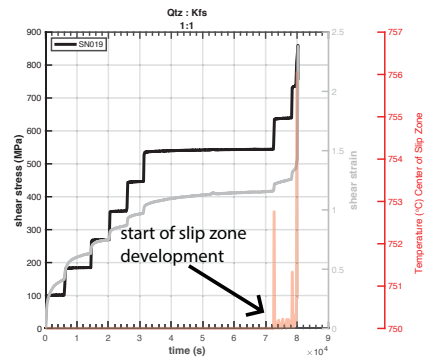

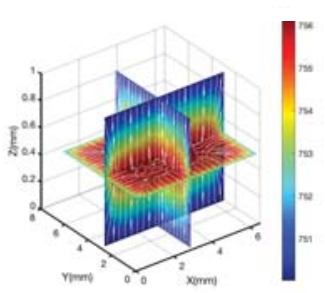

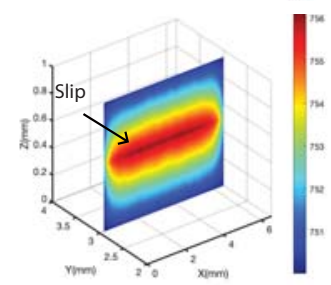

Figure 18. Heat flow simulation of experiment SN019. a) A plot of stress, strain rate, and temperature vs. time. Temperature is plotted for the center of the sample. Right figures display the end-time temperature distribution on cross-sections of the cube. b) Temperature vs. time with a slip zone introduced at the end of the experiment. The Slip zone is introduced as a horizontal layer. The cross-sections show the relative increase of temperature at the slip zone. 


\section{References}

Aharonov, E., \& Scholz, C. H. (2019). The brittle-ductile transition predicted by a physicsbased friction law. Journal of Geophysical Research: Solid Earth, 124(3), 2721-2737.

Aretusini, S., Mittempergher, S., Plümper, O., Spagnuolo, E., Gualtieri, A., \& Di Toro, G. (2017). Production of nanoparticles during experimental deformation of smectite and implications for seismic slip. Earth and Planetary Science Letters, 463, 221-231.

Beall, A., Fagereng, A., \& Ellis, S. (2019). Fracture and weakening of jammed subduction shear zones, leading to the generation of slow slip events. Geochemistry Geophysics Geosystems.

Bos, B., \& Spiers, C. J. (2002). Frictional-viscous flow of phyllosilicate-bearing fault rock: Microphysical model and implications for crustal strength profiles. Journal of Geophysical Research: Solid Earth, 107(B2), ECV-1.

Brace, W. F., \& Kohlstedt, D. L. (1980). L Limits on lithospheric stress imposed by laboratory experiments. Journal of Geophysical Research: Solid Earth, 85(B11), 62486252. doi: 10.1029/jb085ib11p06248

Braeck, S., \& Podladchikov, Y. (2007). Spontaneous thermal runaway as an ultimate failure mechanism of materials. Physical Review Letters, 98(9), 095504.

Bukovská, Z., Jeřábek, P., \& Morales, L. F. (2016). Major softening at brittle-ductile transition due to interplay between chemical and deformation processes: An insight from evolution of shear bands in the south armorican shear zone. Journal of Geophysical Research: Solid Earth, 121(2), 1158-1182.

Burdette, E., \& Hirth, G. (2018). Antigorite slip during dehydration: Rig compliance and loading condition experiments. AGUFM, 2018, T14B-05.

Bürgmann, R., \& Dresen, G. (2008). Rheology of the Lower Crust and Upper Mantle: Evidence from Rock Mechanics, Geodesy, and Field Observations. Annual Review of Earth and Planetary Sciences, 36(1), 531-567. doi: 10.1146/annurev.earth.36.031207 .124326

Carter, N. L., \& Tsenn, M. C. (1987). Flow properties of continental lithosphere. Tectonophysics, 136(1-2), 27-63.

Chester, F. M. (1988). The brittle-ductile transition in a deformation-mechanism map for halite. Tectonophysics, 154(1-2), 125-136.

Daniel, I., Gillet, P., McMillan, P. F., Wolf, G., \& Verhelst, M. A. (1997). High-pressure behavior of anorthite: Compression and amorphization. Journal of Geophysical Research: Solid Earth, 102(B5), 10313-10325.

Delle Piane, C., Bourdet, J., Josh, M., Clennell, M. B., Rickard, W. D., Saunders, M., ... Raven, M. D. (2018). Organic matter network in post-mature marcellus shale: Effects on petrophysical properties. AAPG Bulletin, 102(11), 2305-2332.

Di Toro, G., Goldsby, D. L., \& Tullis, T. E. (2004). Friction falls towards zero in quartz rock as slip velocity approaches seismic rates. Nature, 427(6973), 436-439.

Fagereng, Å., \& Sibson, R. H. (2010). Melange rheology and seismic style. Geology, 38(8), $751-754$.

Falk, M. L., \& Langer, J. S. (2011). Deformation and failure of amorphous, solidlike materials. Annu. Rev. Condens. Matter Phys., 2(1), 353-373.

Fecht, H. (1992). Defect-induced melting and solid-state amorphization. Nature, 356(6365), 133-135.

FitzGerald, J., \& Stünitz, H. (1993). Deformation of granitoids at low metamorphic grade. i: Reactions and grain size reduction. Tectonophysics, 221(3-4), 269-297.

Fossen, H., \& Tikoff, B. (1993). The deformation matrix for simultaneous simple shearing, pure shearing and volume change, and its application to transpression-transtension tectonics. Journal of Structural Geology, 15(3-5), 413-422.

Fredrich, J. T., Evans, B., \& Wong, T.-F. (1989). Micromechanics of the brittle to plastic transition in carrara marble. Journal of Geophysical Research: Solid Earth, 94(B4), 4129-4145.

Fredrich, J. T., Evans, B., \& Wong, T.-F. (1990). Effect of grain size on brittle and semibrittle strength: Implications for micromechanical modelling of failure in compression. 
Journal of Geophysical Research: Solid Earth, 95(B7), 10907-10920.

Fusseis, F., \& Handy, M. (2008). Micromechanisms of shear zone propagation at the brittleviscous transition. Journal of Structural Geology, 30(10), 1242-1253.

Gerald, J. D. F., Boland, J. N., McLaren, A. C., Ord, A., \& Hobbs, B. E. (1991). Microstructures in water-weakened single crystals of quartz. Journal of Geophysical Research: Solid Earth, 96(B2), 2139-2155.

Ghaffari, H., \& Pec, M. (2020). An ultrasound probe array for a high-pressure, hightemperature solid medium deformation apparatus. Review of Scientific Instruments, 91(8), 085117.

Goetze, C., \& Evans, B. (1979). Stress and temperature in the bending lithosphere as constrained by experimental rock mechanics. Geophysical Journal of the Royal Astronomical Society, 59(3), 463-478. doi: 10.1111/j.1365-246X.1979.tb02567.x

Goldsby, D. L., \& Tullis, T. E. (2002). Low frictional strength of quartz rocks at subseismic slip rates. Geophysical research letters, 29(17), 25-1.

Hadizadeh, J., Tullis, T. E., White, J. C., \& Konkachbaev, A. I. (2015). Shear localization, velocity weakening behavior, and development of cataclastic foliation in experimental granite gouge. Journal of Structural Geology, 71, 86-99.

Hayman, N. W., \& Lavier, L. L. (2014). The geologic record of deep episodic tremor and slip. Geology, 42(3), 195-198.

Hayward, K. S., Cox, S. F., Gerald, J. D. F., Slagmolen, B. J., Shaddock, D. A., Forsyth, P. W., ... Hawkins, R. P. (2016). Mechanical amorphization, flash heating, and frictional melting: Dramatic changes to fault surfaces during the first millisecond of earthquake slip. Geology, 44(12), 1043-1046.

Heilbronner, R. (2002). Analysis of bulk fabrics and microstructure variations using tesselations of autocorrelation functions. Computers and Geosciences, 28(4), 447-455. doi: 10.1016/S0098-3004(01)00088-7

Heilbronner, R., \& Barrett, S. (2013). Image analysis in earth sciences: microstructures and textures of earth materials (Vol. 129). Springer Science \& Business Media.

Heilbronner, R., \& Kilian, R. (2017). The grain size(s) of Black Hills Quartzite deformed in the dislocation creep regime. Solid Earth Discussions, 1-57. doi: 10.5194/se-2017 $-30$

Hirth, G., \& Tullis, J. (1994). The brittle-plastic transition in experimentally deformed quartz aggregates. Journal of Geophysical Research, 99(B6). doi: 10.1029/93jb02873

Jacquey, A. B., \& Cacace, M. (2020a). Multiphysics modeling of a brittle-ductile lithosphere: 1. explicit visco-elasto-plastic formulation and its numerical implementation. Journal of Geophysical Research: Solid Earth, 125(1), e2019JB018474.

Jacquey, A. B., \& Cacace, M. (2020b). Multiphysics modeling of a brittle-ductile lithosphere: 2. semi-brittle, semi-ductile deformation and damage rheology. Journal of Geophysical Research: Solid Earth, 125(1), e2019JB018475.

Kaneki, S., Oohashi, K., Hirono, T., \& Noda, H. (2020). Mechanical amorphization of synthetic fault gouges during rotary-shear friction experiments at sub-seismic to seismic slip velocities. Journal of Geophysical Research: Solid Earth, e2020JB019956.

Kelemen, P. B., \& Hirth, G. (2007). A periodic shear-heating mechanism for intermediatedepth earthquakes in the mantle. Nature, 446(7137), 787-790.

Kilian, R., \& Heilbronner, R. (2017). Analysis of crystallographic preferred orientations of experimentally deformed Black Hills Quartzite. Solid Earth, 8(5), 1095-1117. doi: 10 $.5194 / \mathrm{se}-8-1095-2017$

Kohlstedt, D., Evans, B., \& Mackwell, S. (1995). Strength of the lithosphere: Constraints imposed by laboratory experiments. Journal of Geophysical Research: Solid Earth, 100(B9), 17587-17602.

Kumamoto, K. M., Thom, C. A., Wallis, D., Hansen, L. N., Armstrong, D. E., Warren, J. M., ... Wilkinson, A. J. (2017). Size effects resolve discrepancies in 40 years of work on low-temperature plasticity in olivine. Science advances, 3(9), e1701338.

Lavier, L. L., Bennett, R. A., \& Duddu, R. (2013). Creep events at the brittle ductile transition. Geochemistry, Geophysics, Geosystems, 14(9), 3334-3351. 
Machon, D., Meersman, F., Wilding, M., Wilson, M., \& McMillan, P. (2014). Pressureinduced amorphization and polyamorphism: Inorganic and biochemical systems. Progress in Materials Science, 61, 216-282.

Mainprice, D., Hielscher, R., \& Schaeben, H. (2011). Calculating anisotropic physical properties from texture data using the mtex open-source package. Geological Society, London, Special Publications, 360(1), 175-192.

Mancktelow, N. S., \& Pennacchioni, G. (2004). The influence of grain boundary fluids on the microstructure of quartz-feldspar mylonites. Journal of Structural Geology, 26(1), 47-69.

Marti, S., Stünitz, H., Heilbronner, R., \& Plümper, O. (2020). Amorphous material in experimentally deformed mafic rock and its temperature dependence: Implications for fault rheology during aseismic creep and seismic rupture. Journal of Structural Geology, 104081.

Marti, S., Stünitz, H., Heilbronner, R., Plümper, O., \& Drury, M. ～(2017). Experimental investigation of the brittle-viscous transition in mafic rocks-interplay between fracturing, reaction, and viscous deformation. Journal of Structural Geology, 105, 62-79.

Menegon, L., Piazolo, S., \& Pennacchioni, G. (2011). The effect of dauphiné twinning on plastic strain in quartz. Contributions to Mineralogy and Petrology, 161(4), 635-652.

Menegon, L., Stünitz, H., Nasipuri, P., Heilbronner, R., \& Svahnberg, H. (2013). Transition from fracturing to viscous flow in granulite facies perthitic feldspar (lofoten, norway). Journal of Structural Geology, 48, 95-112.

Meyers, M. A., Mishra, A., \& Benson, D. J. (2006). Mechanical properties of nanocrystalline materials. Progress in materials science, 51(4), 427-556.

Molnar, P. (2020). The brittle-plastic transition, earthquakes, temperatures, and strain rates. Journal of Geophysical Research: Solid Earth, 125(7), e2019JB019335.

Niemeijer, A., \& Spiers, C. (2007). A microphysical model for strong velocity weakening in phyllosilicate-bearing fault gouges. Journal of Geophysical Research: Solid Earth, 112(B10).

Noda, H., \& Shimamoto, T. (2012). Transient behavior and stability analyses of halite shear zones with an empirical rate-and-state friction to flow law. Journal of Structural Geology, 38, 234-242.

Nojiri, H., Okuno, M., Okudera, H., Mizukami, T., \& Arai, S. ～(2013). Structural change of alkali feldspar by ball milling. Journal of Mineralogical and Petrological Sciences, 121122.

Okazaki, K., \& Hirth, G. (2020). Deformation of mafic schists from subducted oceanic crust at high pressure and temperature conditions. Tectonophysics, 774, 228217.

Okudaira, T., Jeřábek, P., Stünitz, H., \& Fusseis, F. (2015). High-temperature fracturing and subsequent grain-size-sensitive creep in lower crustal gabbros: Evidence for coseismic loading followed by creep during decaying stress in the lower crust? Journal of Geophysical Research: Solid Earth, 120(5), 3119-3141.

Parisio, F., Lehmann, C., \& Nagel, T. (n.d.). A model of failure and localization of basalt at temperature and pressure conditions spanning the brittle-ductile transition. Journal of Geophysical Research: Solid Earth, e2020JB020539.

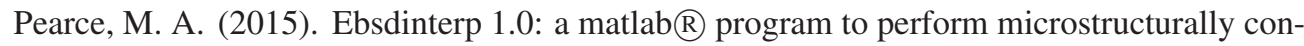
strained interpolation of ebsd data. Microscopy and Microanalysis, 21(4), 985-993.

Pec, M., Stünitz, H., \& Heilbronner, R. (2012). Semi-brittle deformation of granitoid gouges in shear experiments at elevated pressures and temperatures. Journal of Structural Geology, 38, 200-221. doi: 10.1016/j.jsg.2011.09.001

Pec, M., Stünitz, H., Heilbronner, R., \& Drury, M. ～(2016). Semi-brittle flow of granitoid fault rocks in experiments. Journal of Geophysical Research: Solid Earth, 121(3), 1677-1705.

Pec, M., Stünitz, H., Heilbronner, R., Drury, M., \& de Capitani, C. (2012). Origin of pseudotachylites in slow creep experiments. Earth and Planetary Science Letters, 355-356, 299-310. doi: 10.1016/j.epsl.2012.09.004

Pennacchioni, G., Di Toro, G., Brack, P., Menegon, L., \& Villa, I. M. ～(2006). Brittle- 
ductile-brittle deformation during cooling of tonalite (adamello, southern italian alps). Tectonophysics, 427(1-4), 171-197.

Pennacchioni, G., \& Mancktelow, N. S. (2007). Nucleation and initial growth of a shear zone network within compositionally and structurally heterogeneous granitoids under amphibolite facies conditions. Journal of Structural Geology, 29(11), 1757-1780.

Phillips, N. J., Motohashi, G., Ujiie, K., \& Rowe, C. D. (2020). Evidence of localized failure along altered basaltic blocks in tectonic mélange at the updip limit of the seismogenic zone: Implications for the shallow slow earthquake source. Geochemistry, Geophysics, Geosystems, 21(7), e2019GC008839.

Précigout, J., Stünitz, H., Pinquier, Y., Champallier, R., \& Schubnel, A. （2018). Highpressure, high-temperature deformation experiment using the new generation griggstype apparatus. JoVE (Journal of Visualized Experiments)(134), e56841.

Rahl, J. M., McGrew, A. J., Fox, J. A., Latham, J. R., \& Gabrielson, T. ～(2018). Rhombdominated crystallographic preferred orientations in incipiently deformed quartz sandstones: A potential paleostress indicator for quartz-rich rocks. Geology, 46(3), 195-198.

Reber, J. E., Lavier, L. L., \& Hayman, N. W. (2015). Experimental demonstration of a semibrittle origin for crustal strain transients. Nature Geoscience, 8(9), 712-715. doi: 10 $.1038 /$ ngeo2496

Reber, J. E., \& Pec, M. (2018). Comparison of brittle-and viscous creep in quartzites: Implications for semi-brittle flow of rocks. Journal of Structural Geology, 113, 90-99.

Richet, P., \& Gillet, P. (1997). Pressure-induced amorphization of minerals; a review. European Journal of Mineralogy, 9(5), 907-933.

Richter, B., Stünitz, H., \& Heilbronner, R. $\quad$ (2018). The brittle-to-viscous transition in polycrystalline quartz: An experimental study. Journal of Structural Geology, 114(September 2017), 1-21. Retrieved from https://doi.org/10.1016/ j.jsg.2018.06.005 doi: 10.1016/j.jsg.2018.06.005

Ronde, A. A. d. (2004). Mineral reaction and deformation in plagioclase-olivine composites: An experimental study (Unpublished doctoral dissertation). University_of_Basel.

Rowe, C. D., Lamothe, K. G., Rempe, M., Andrews, M., Mitchell, T. M., Di Toro, G., ... Gonzalez, C. (2019). Earthquake lubrication and healing caused by amorphous silica powder-experimental wear products compared to natural fault rocks. AGUFM, 2019, MR31A-01.

Rowe, C. D., Moore, J. C., Remitti, F., \& Scientists, I. E. T. (2013). The thickness of subduction plate boundary faults from the seafloor into the seismogenic zone. Geology, 41(9), 991-994.

Roy, A., Perfect, E., Dunne, W. M., \& McKay, L. D. (2007). Fractal characterization of fracture networks: An improved box-counting technique. Journal of Geophysical Research: Solid Earth, 112(B12).

Sammis, C. G., \& Ben-Zion, Y. (2008). Mechanics of grain-size reduction in fault zones. Journal of Geophysical Research: Solid Earth, 113(B2).

Sánchez, E. C., Torres, E., Diaz, C., \& Saito, F. (2004). Effects of grinding of the feldspar in the sintering using a planetary ball mill. Journal of materials processing technology, 152(3), 284-290.

Schuh, C. A., Hufnagel, T. C., \& Ramamurty, U. (2007). Mechanical behavior of amorphous alloys. Acta Materialia, 55(12), 4067-4109.

Simpson, C. (1985). Deformation of granitic rocks across the brittle-ductile transition INTRODUCTION DEFORMATION of quartzo-feidspathic rocks at the brittle- ductile transition in deep-seated fault zones commonly produces mylonites in which quartz and mica deform in a ducti. , 7(5).

Sims, M., Jaret, S. J., Carl, E.-R., Rhymer, B., Schrodt, N., Mohrholz, V., ... others (2019). Pressure-induced amorphization in plagioclase feldspars: A time-resolved powder diffraction study during rapid compression. Earth and Planetary Science Letters, 507, $166-174$.

Stünitz, H., \& FitzGerald, J. D. (1993). Deformation of granitoids at low metamorphic 
grade. II: Granular flow in albite-rich mylonites. Tectonophysics, 221(3-4), 299-324. doi: 10.1016/0040-1951(93)90164-F

Stünitz, H., Gerald, J. F., \& Tullis, J. ～(2003). Dislocation generation, slip systems, and dynamic recrystallization in experimentally deformed plagioclase single crystals. Tectonophysics, 372(3-4), 215-233.

Suryanarayana, C. (2001). Mechanical alloying and milling. Progress in materials science, $46(1-2), 1-184$.

Tarantola, A., Diamond, L. W., Stünitz, H., Thust, A., \& Pec, M. (2012). Modification of fluid inclusions in quartz by deviatoric stress. iii: Influence of principal stresses on inclusion density and orientation. Contributions to mineralogy and petrology, 164(3), 537-550.

Toy, V. G., Boulton, C. J., Sutherland, R., Townend, J., Norris, R. J., Little, T. A., ... others (2015). Fault rock lithologies and architecture of the central alpine fault, new zealand, revealed by dfdp-1 drilling. Lithosphere, 7(2), 155-173.

Tullis, J. (1970). Quartz: preferred orientation in rocks produced by dauphiné twinning. Science, 168(3937), 1342-1344.

Verberne, B., Spiers, C., et al. (2017). A quantitative microstructural investigation of depleted and undepleted reservoir sandstones. In 51st us rock mechanics/geomechanics symposium.

Verberne, B. A., de Bresser, J. H., Niemeijer, A. R., Spiers, C. J., de Winter, D. M., \& Plümper, O. (2013). Nanocrystalline slip zones in calcite fault gouge show intense crystallographic preferred orientation: Crystal plasticity at sub-seismic slip rates at $18-150 \mathrm{c}$. Geology, 41(8), 863-866.

Verberne, B. A., Plümper, O., de Winter, D. M., \& Spiers, C. J. (2014). Superplastic nanofibrous slip zones control seismogenic fault friction. Science, 346(6215), 1342-1344.

Verberne, B. A., van den Ende, M., Chen, J., Niemeijer, A. R., \& Spiers, C. J. (2020). The physics of fault friction: Insights from experiments on simulated gouges at low shearing velocities. Solid Earth Discussions, 1-37.

Wedepohl, K. H. (1995). The composition of the continental crust. Geochimica et cosmochimica Acta, 59(7), 1217-1232.

Weiss, L., \& Wenk, H. (1983). Experimentally produced pseudotachylite-like veins in gabbro. Tectonophysics, 96(3-4), 299-310.

Wolf, D., Okamoto, P. R., Yip, S., Lutsko, J. F., \& Kluge, M. (1990). Thermodynamic Parallels Between Solid-State Amorphization and Melting. Journal of Materials Research, 5(2), 286-301. doi: 10.1557/JMR.1990.0286

Yund, R. a., \& Blanpied, M. L. (1990). Amorphous Material in High Strain Experimental Fault Gouges. , 95(90). 
Figure 1. 
a)

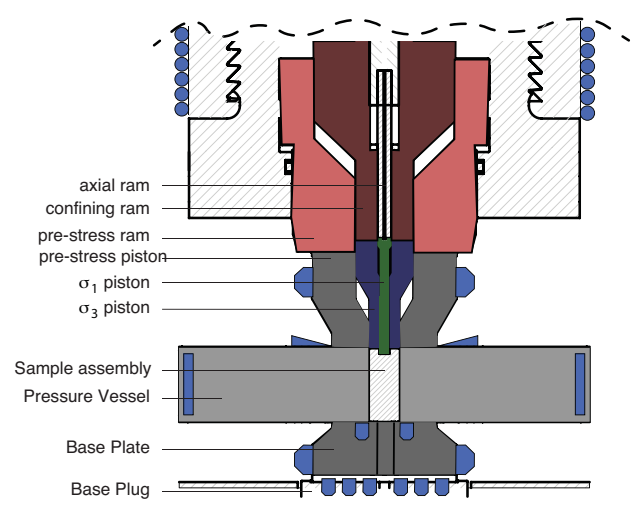

b)

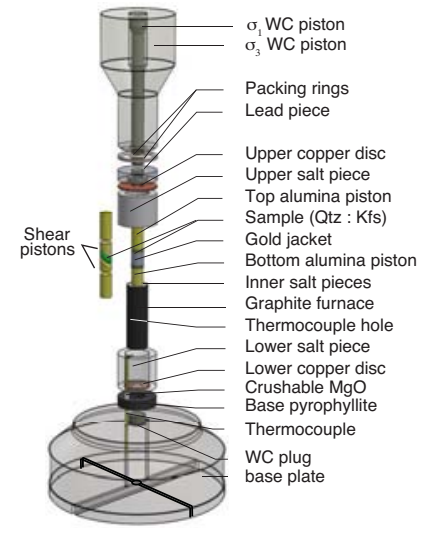

c)

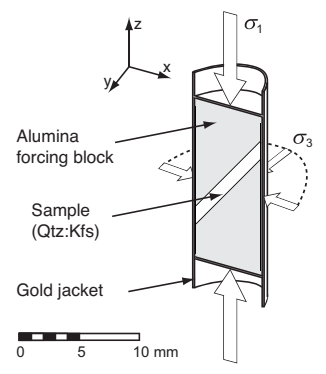


Figure 2. 


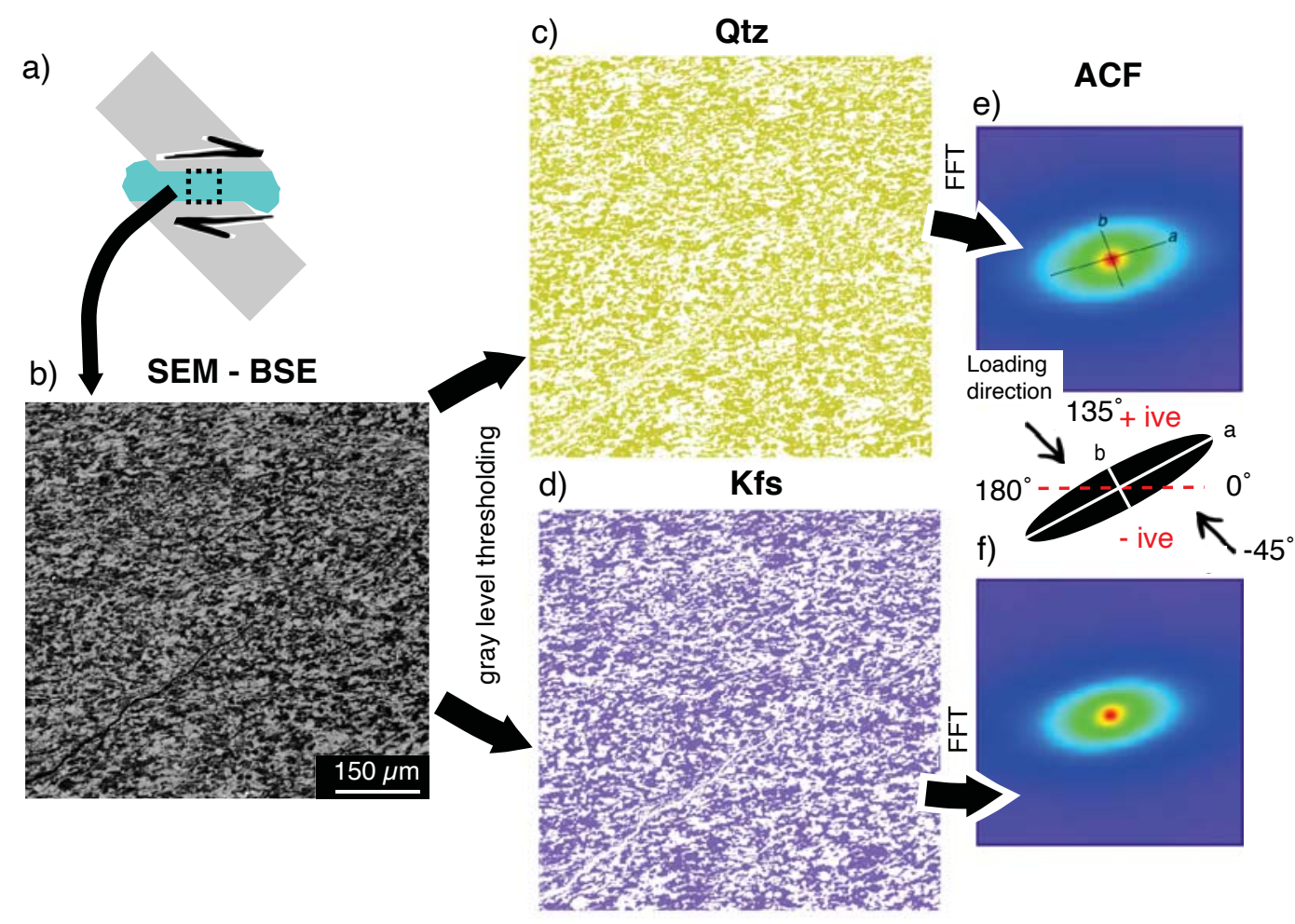


Figure 3. 

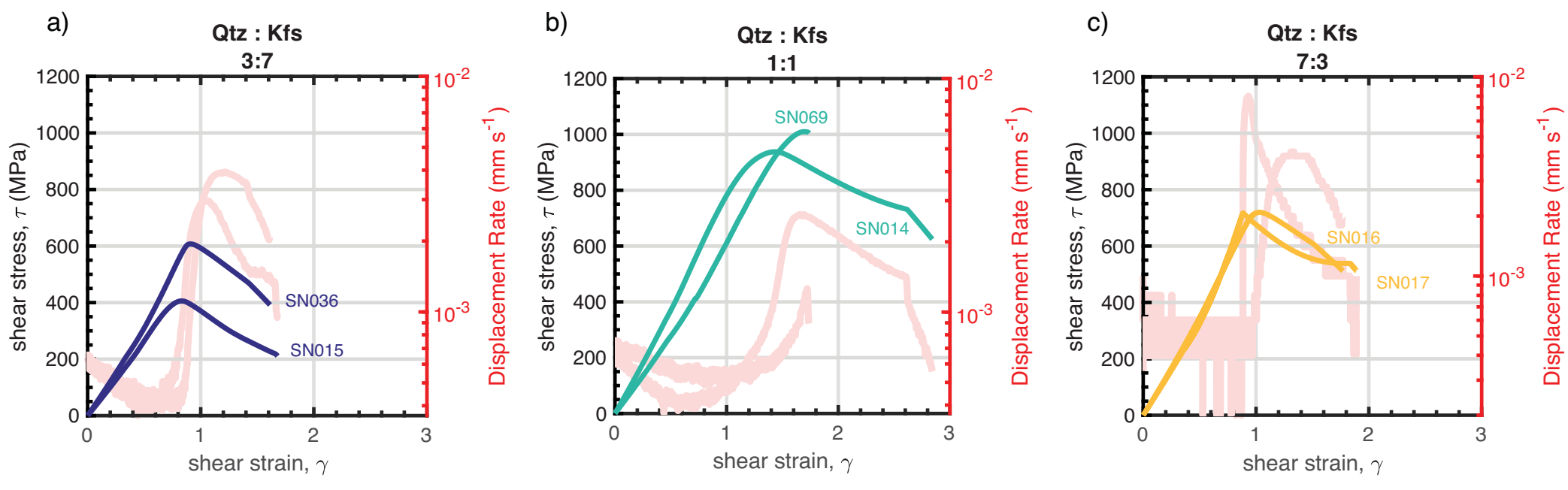
Figure 4. 
Figure 5. 
Figure 6. 
a) Qtz: Kfs $\quad \begin{array}{cc}1: 1 & \text { b) }\end{array}$
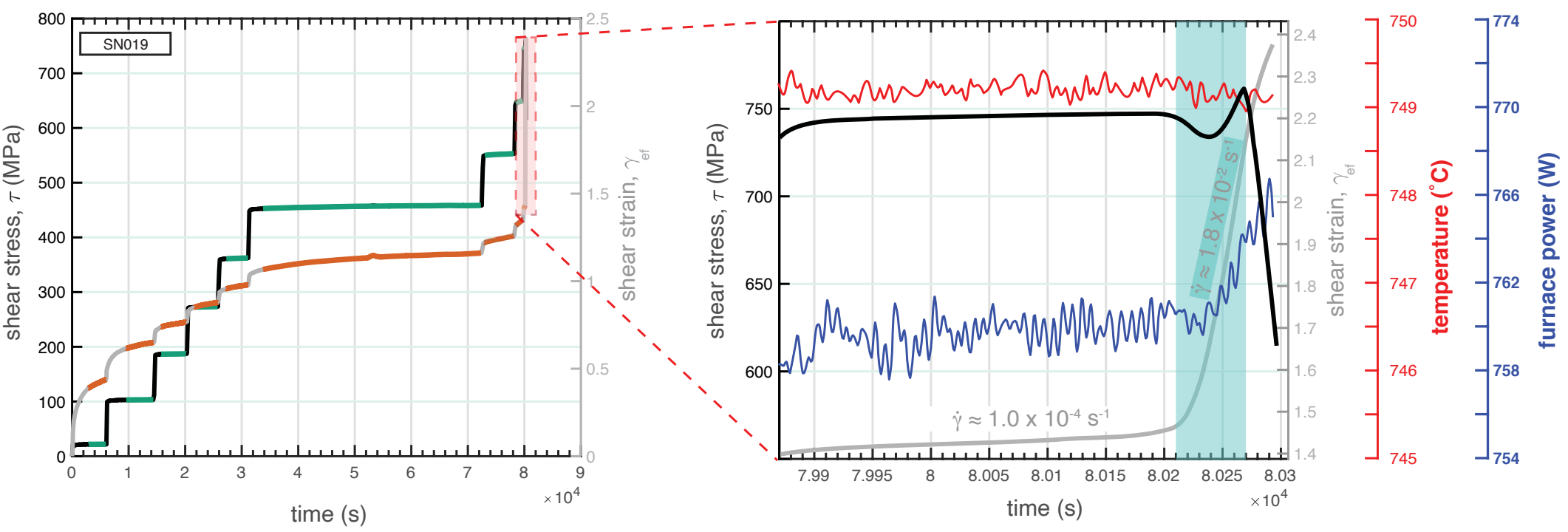

c)

Qtz : Kfs
$3: 7$
d)
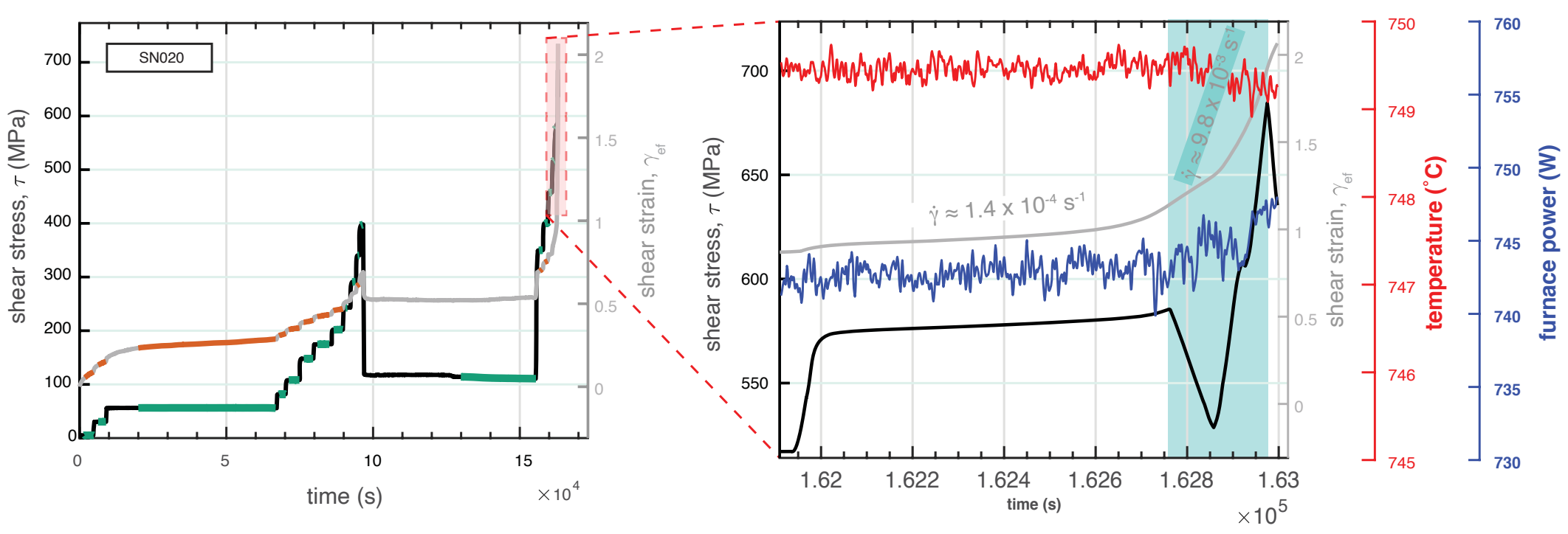
Figure 7. 


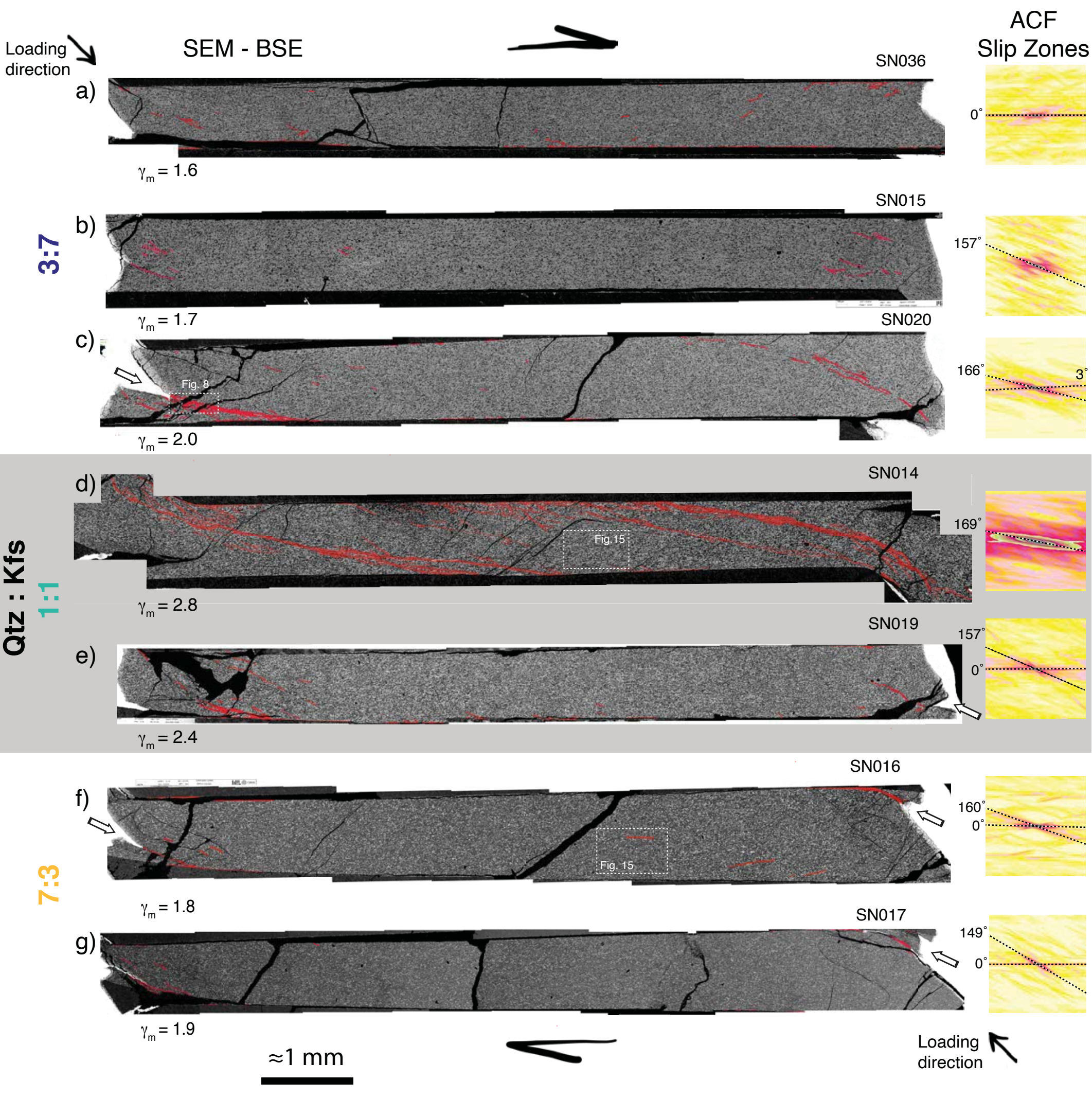


Figure 8. 
Figure 9. 


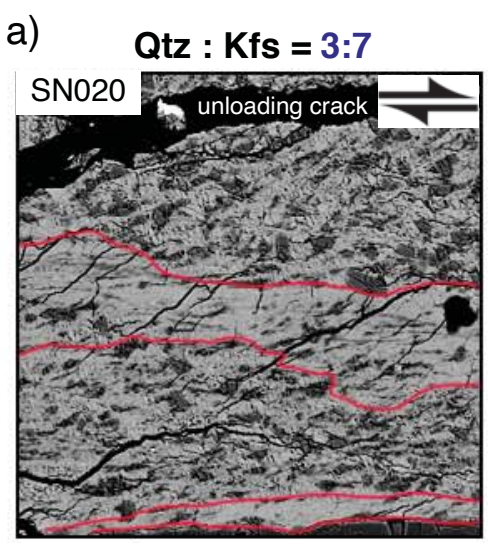

b) Qtz : Kfs = 1:1

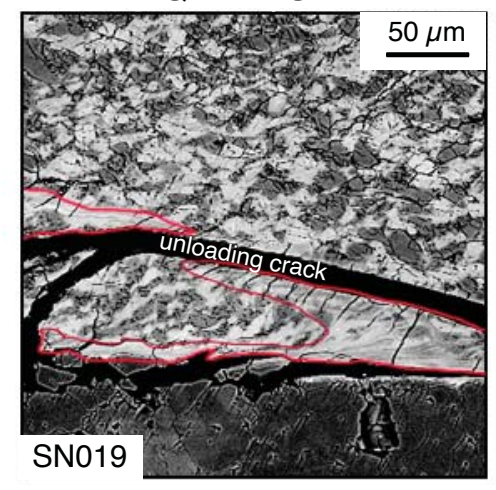

C) Qtz : Kfs = 7:3

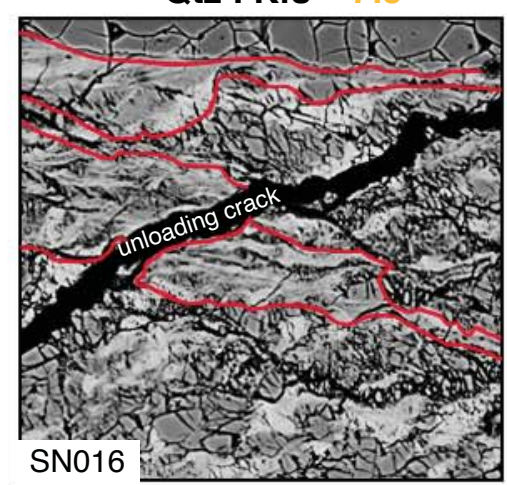


Figure 10. 
a)

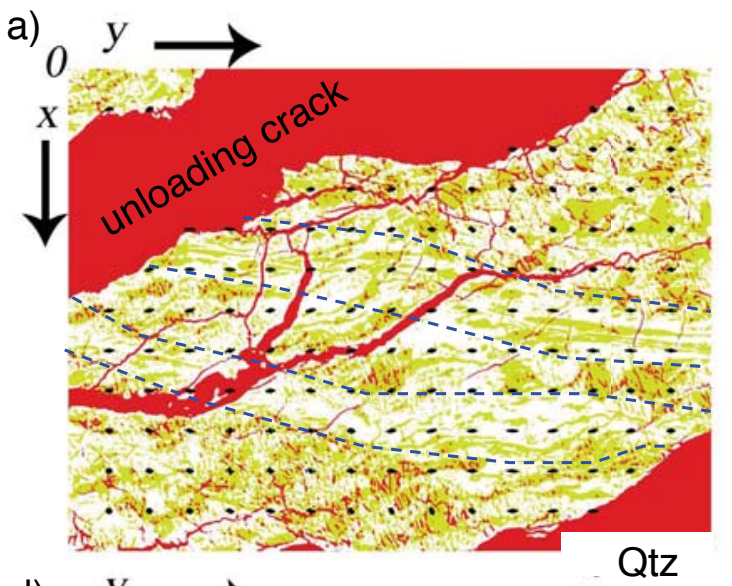

\section{d)}

$$
\text { d) }
$$

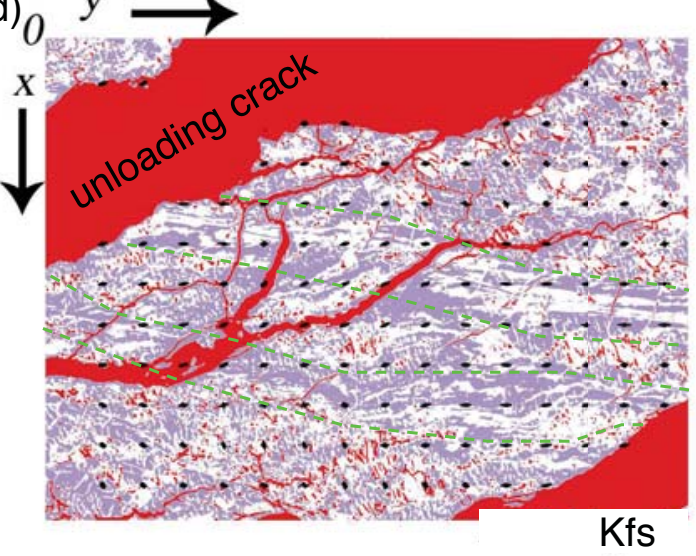

b)

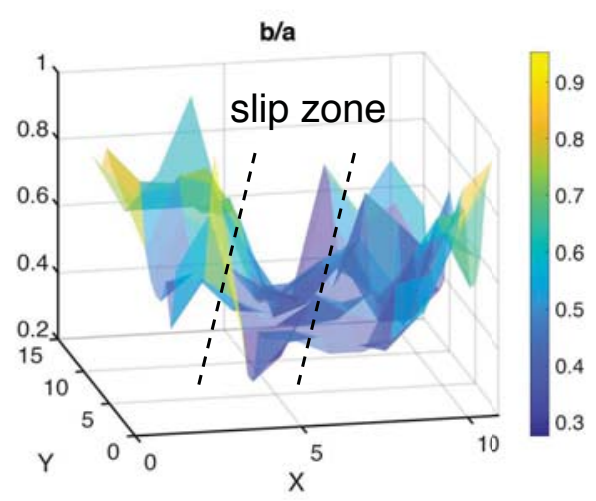

e)

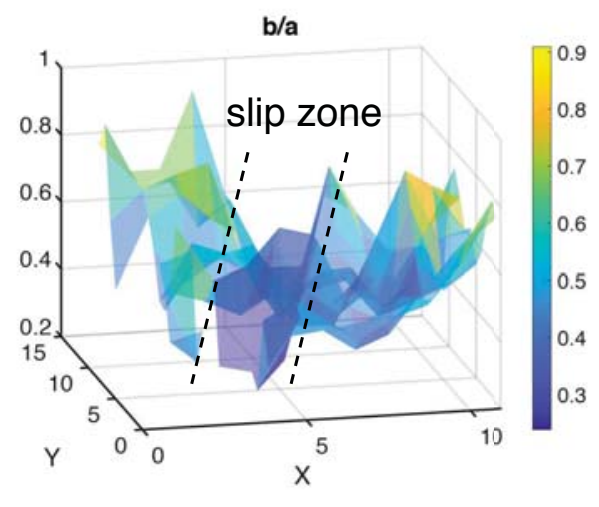

c)

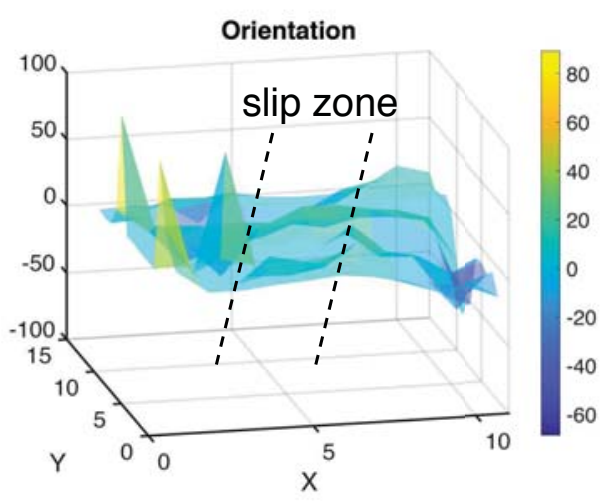

f)

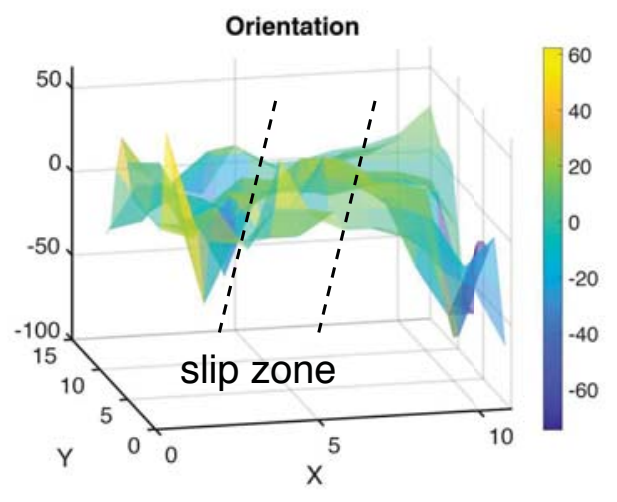


Figure 11. 

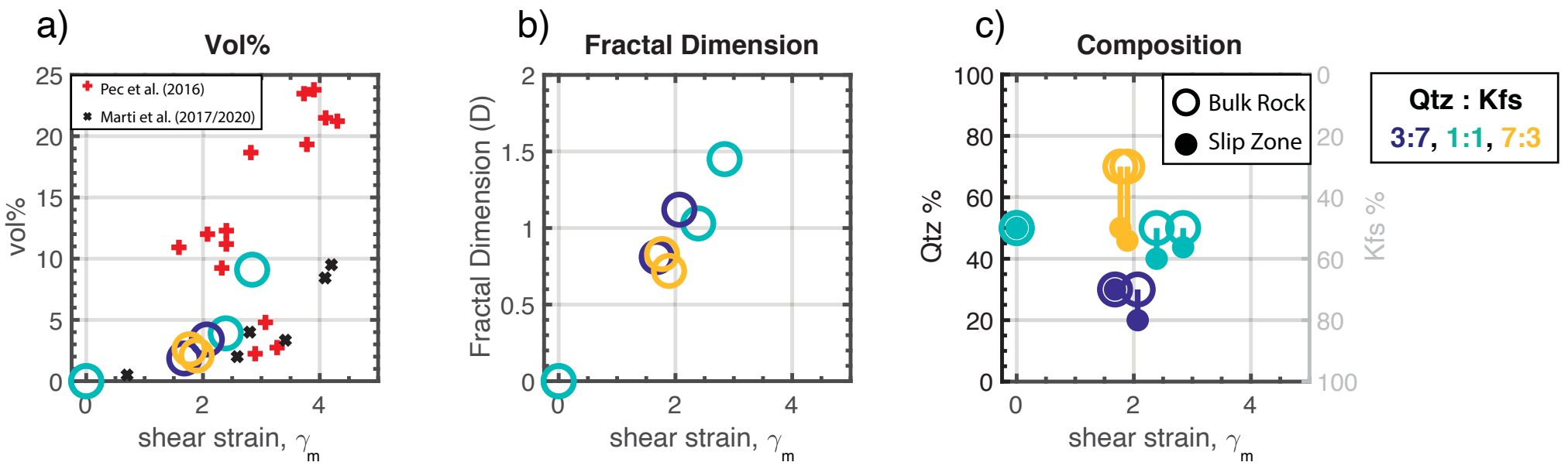
Figure 12. 


\section{$\Rightarrow 200 \mu \mathrm{m}$}

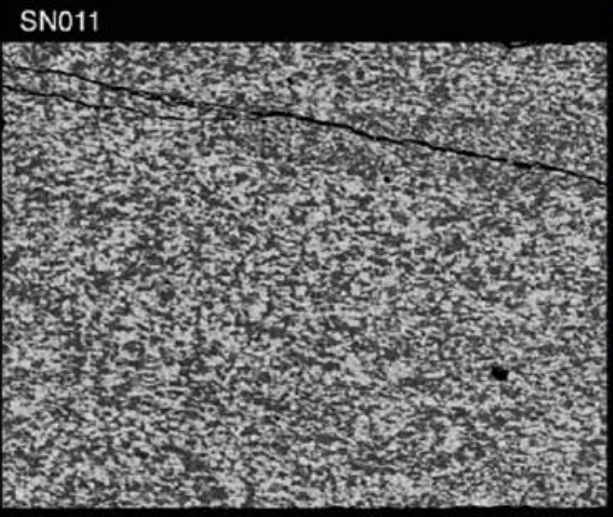

Qtz:Kfs = 1:1

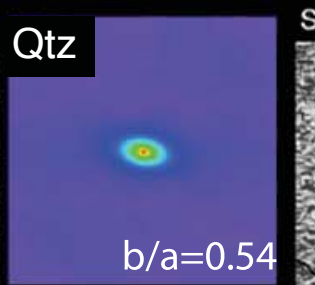

SN012

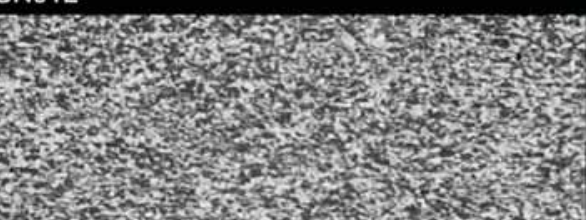

Kfs
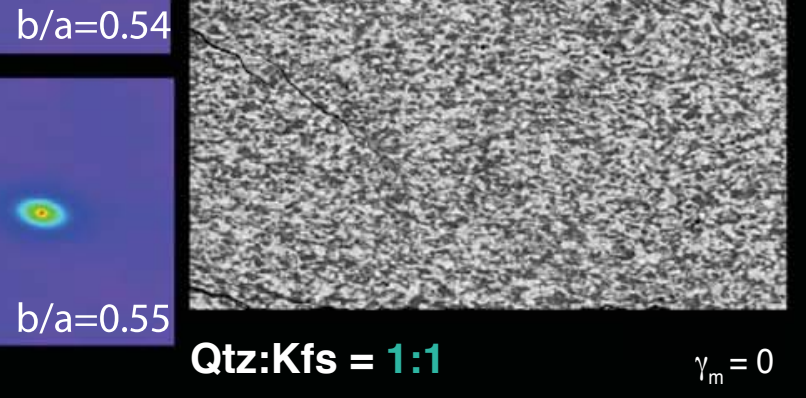

$\gamma_{\mathrm{m}}=0$

Qtz

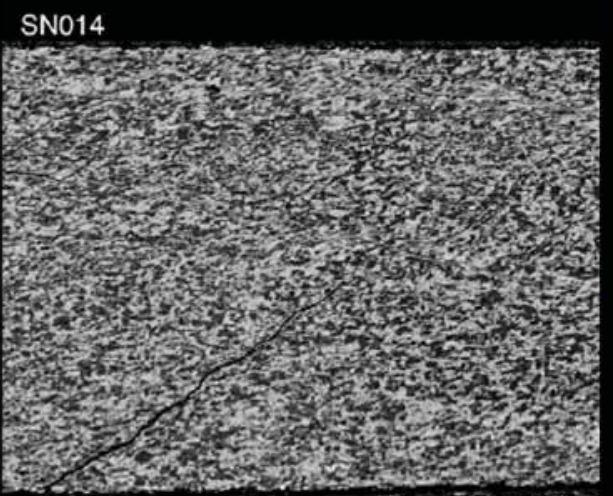

Qtz:Kfs = 1:1

$\gamma_{m}=2.8$

SN016

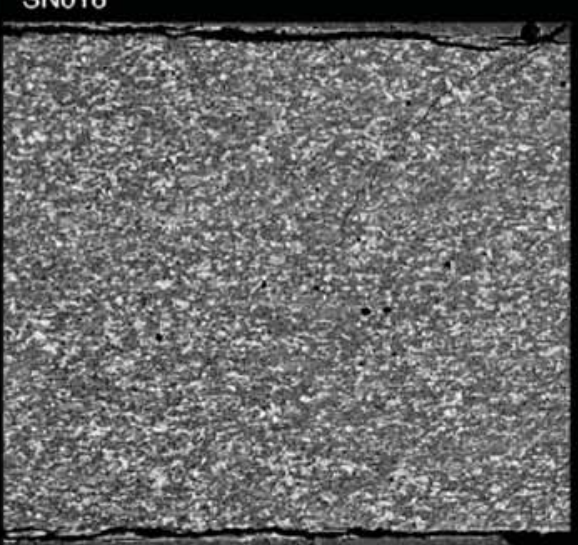

Qtz:Kfs = 7:3 $\gamma_{\mathrm{m}}=1.8$

SN015

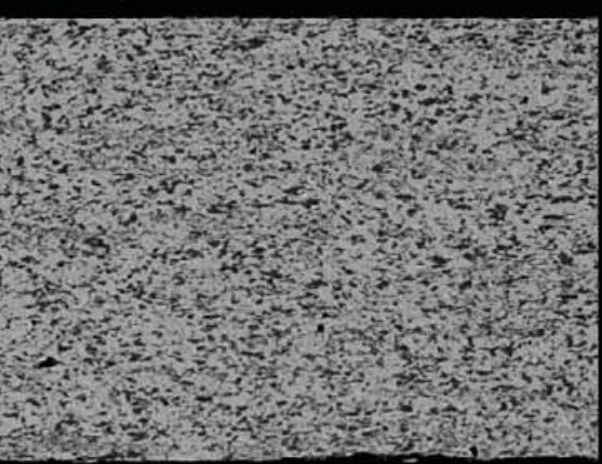

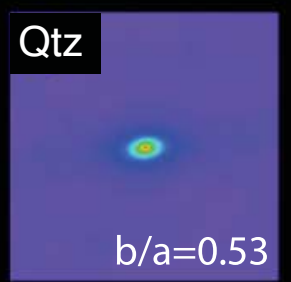

$\mathrm{Kfs}$

$\mathrm{b} / \mathrm{a}=0.52$

Qtz:Kfs = 7:3

SNO20

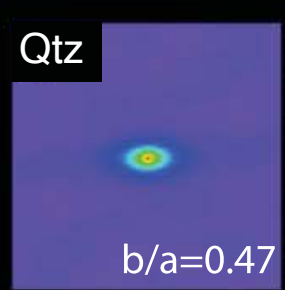

$\mathrm{Kfs}$

$b / a=0.46$

SN017
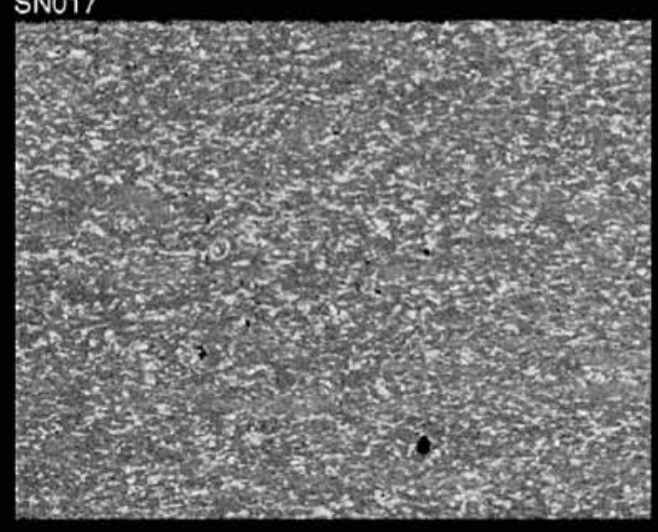

$$
\gamma_{\mathrm{m}}=1.9
$$

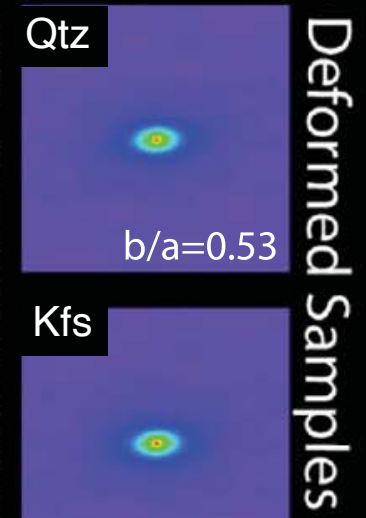

$\mathrm{b} / \mathrm{a}=0.51$

Qtz

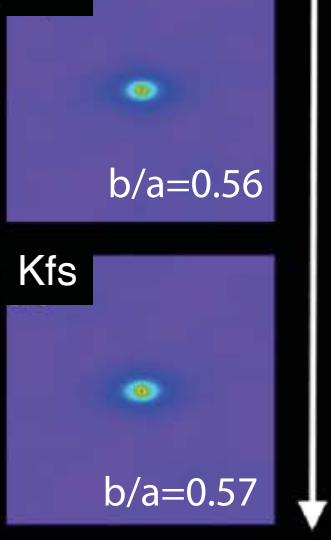

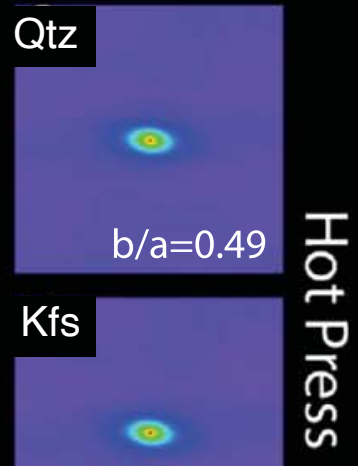

$b / a=0.46$

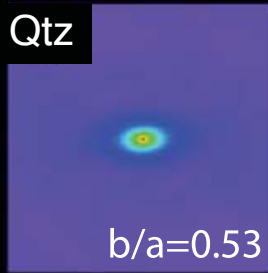

Kfs

$b / a=0.51$

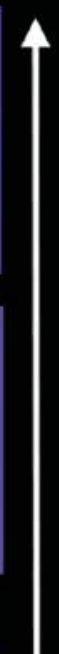


Figure 13. 
a)

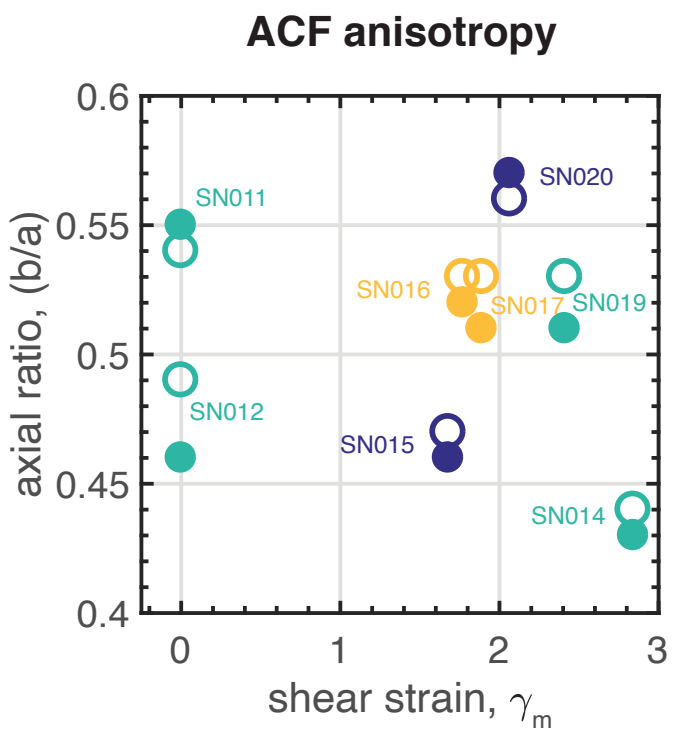

b)
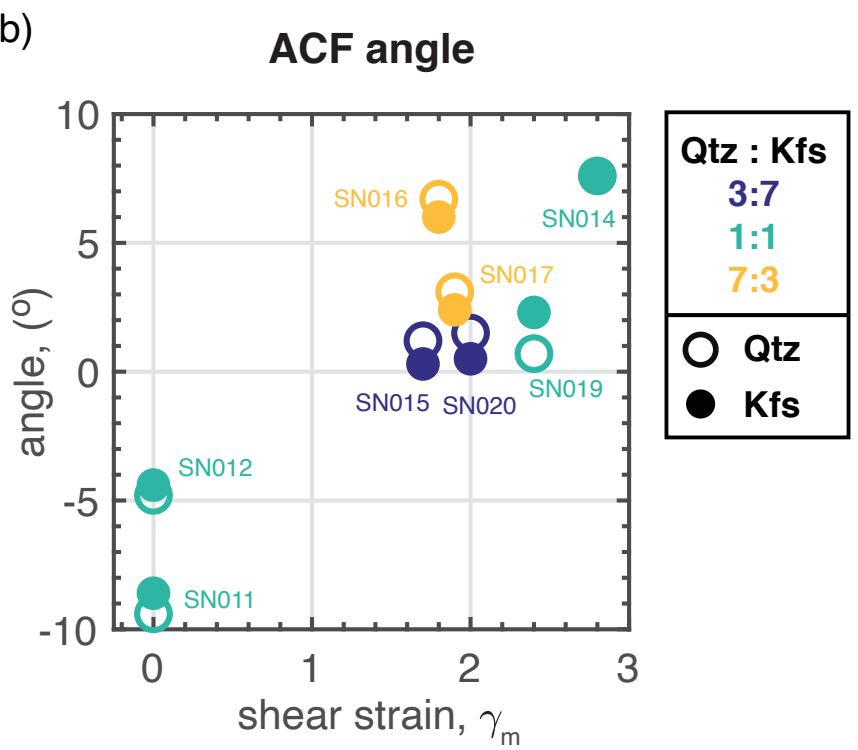
Figure 14. 
a) \} \searrow _ { \text { direction } } ^ { \text { Loaing } } $\gamma_{m}=2.4 \quad$ SN019
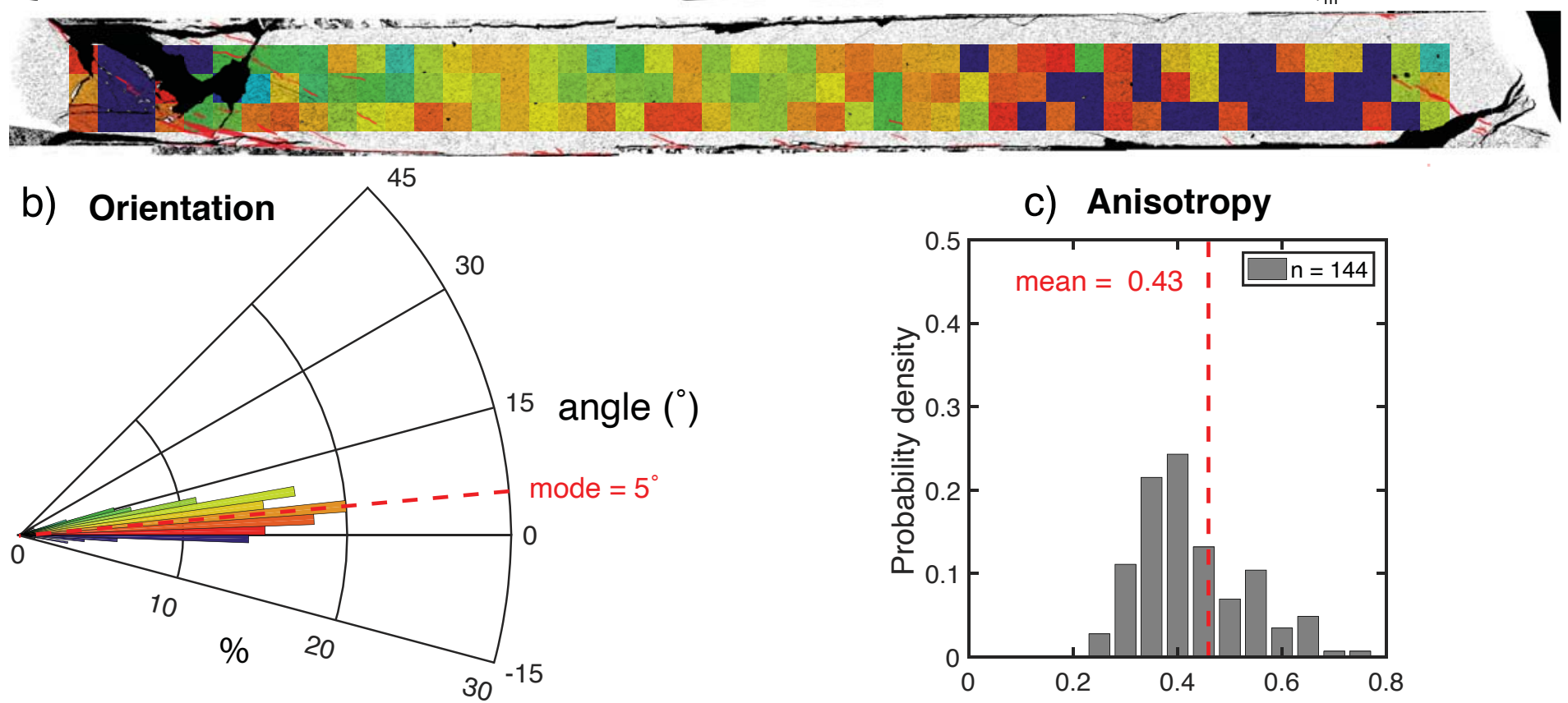

$\approx 1 \mathrm{~mm}$

C) Anisotropy

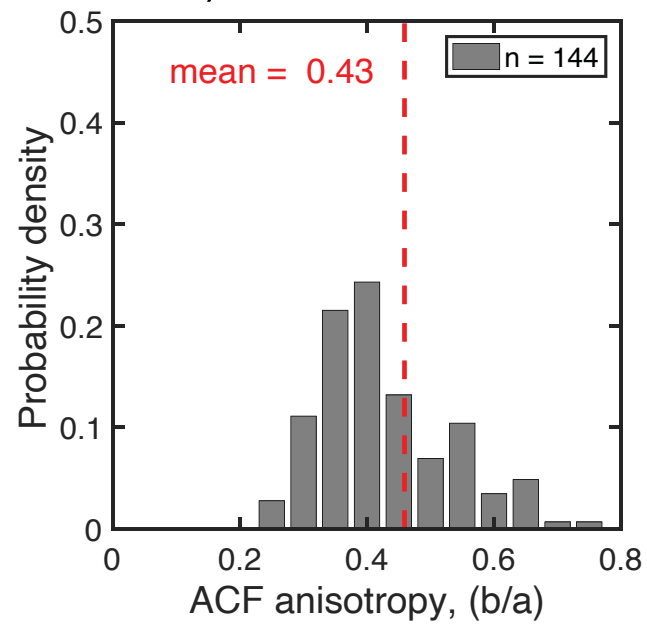

d)

$$
\gamma_{m}=2.8 \quad \text { SN014 }
$$

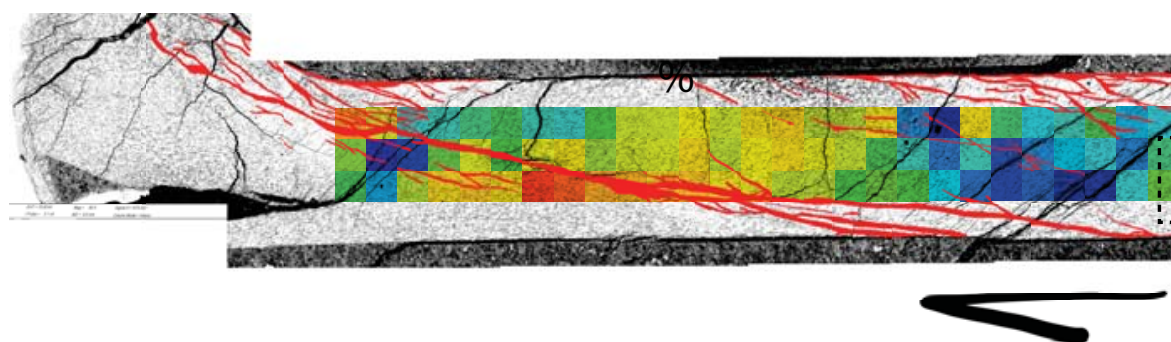

e) Orientation

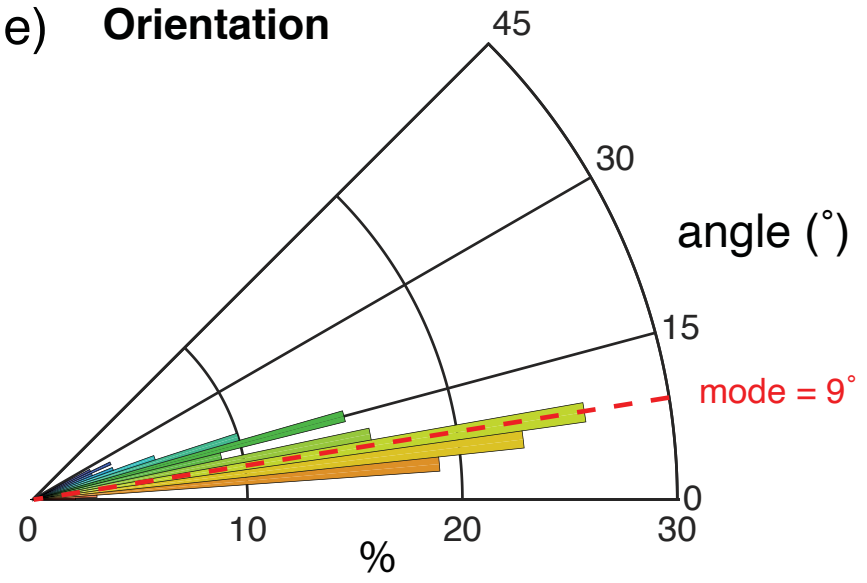

f) Anisotropy

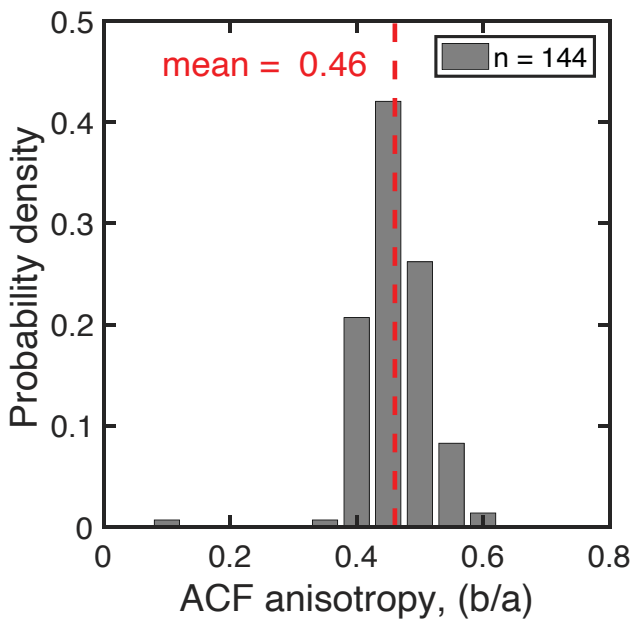

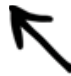

Loading direction 
Figure 15. 
Figure 16. 
a)

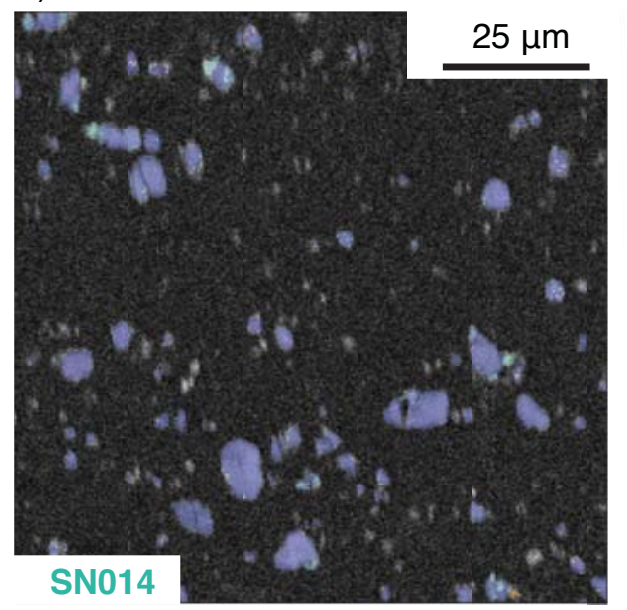

b)

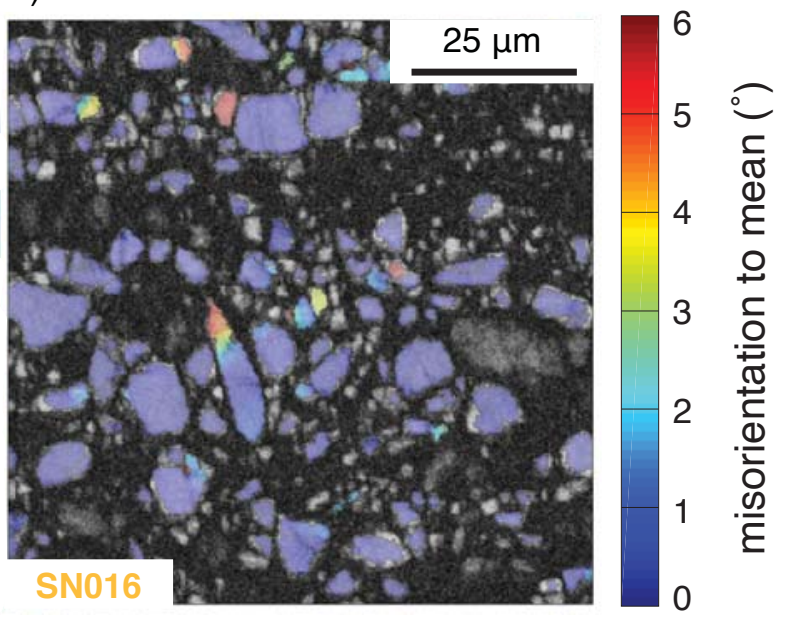


Figure 17. 
a)

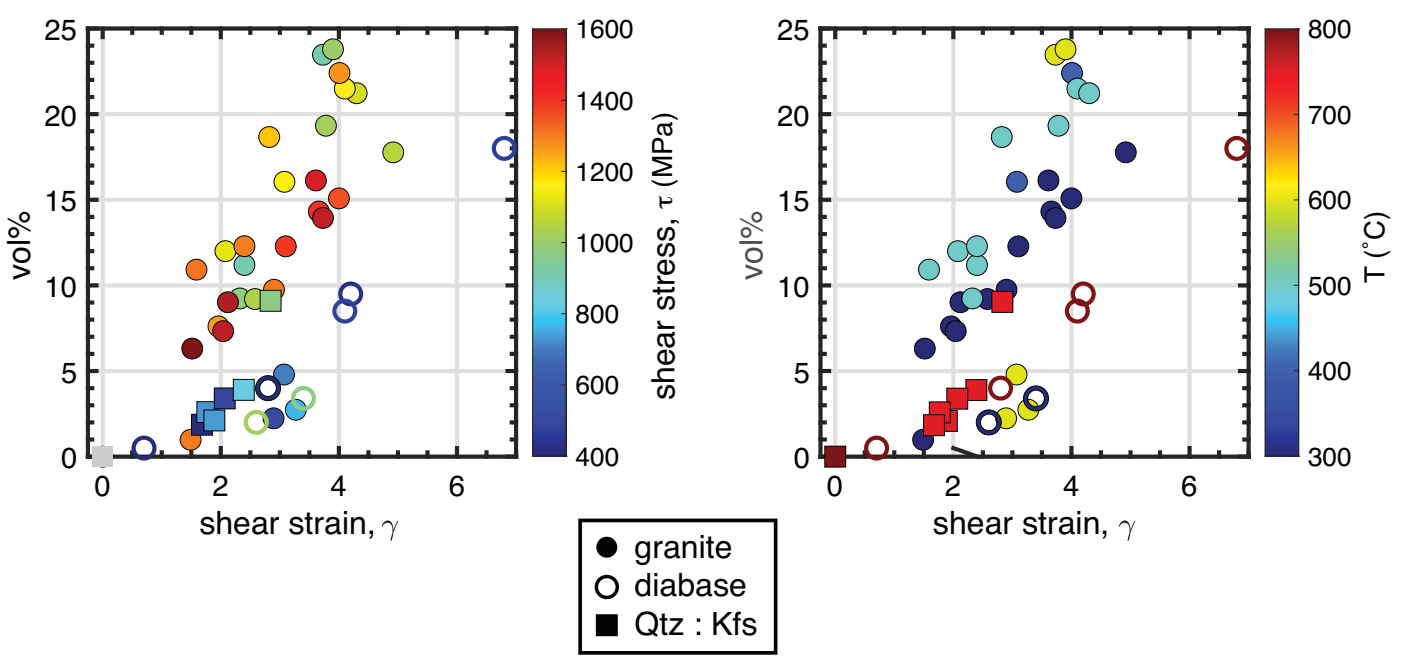

c)

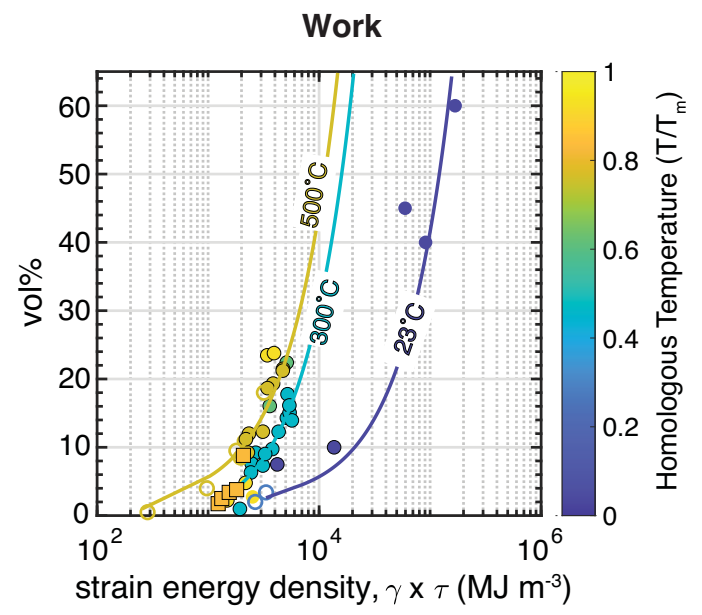


Figure 18. 
Heat Flow Simulation Without Slip Zone Development

a)
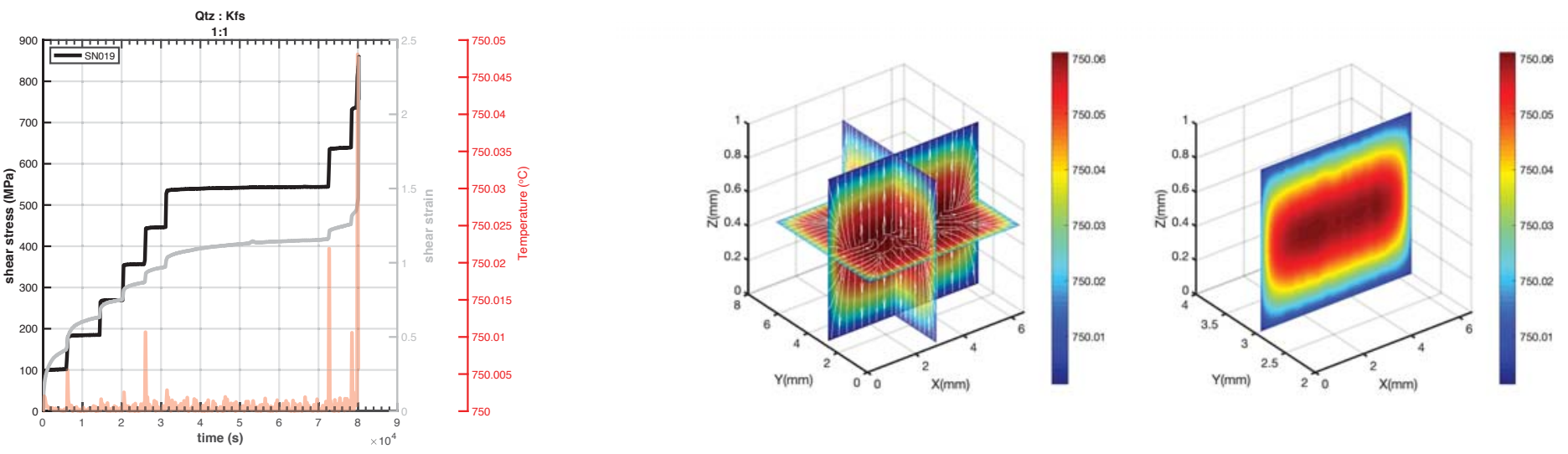

Heat Flow Simulation With Slip Zone Development

b)
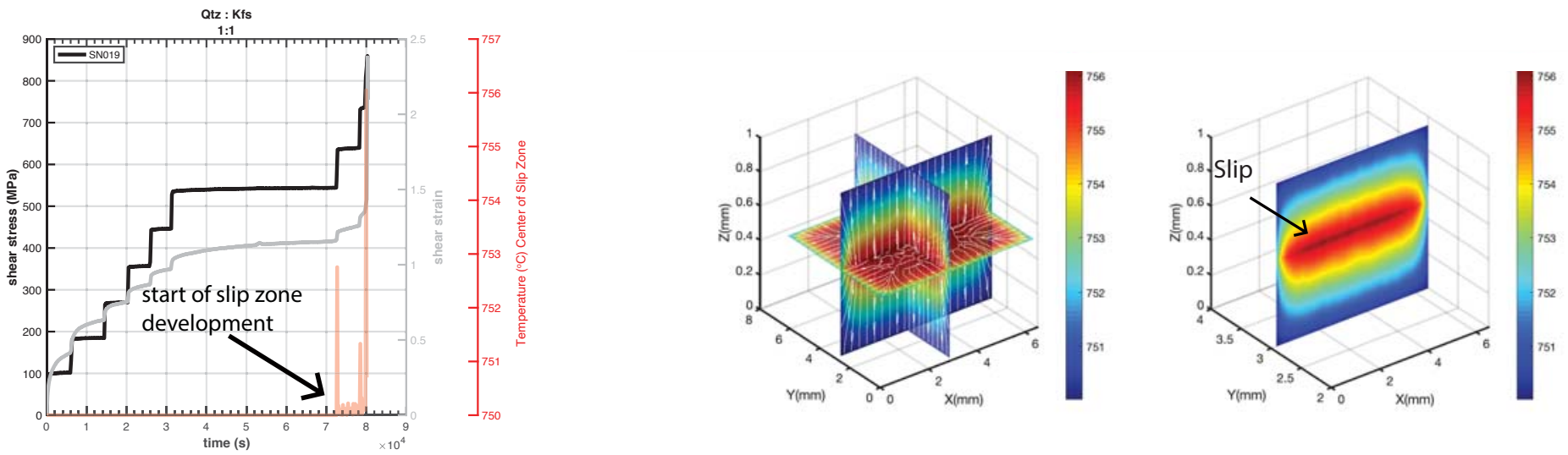